\title{
Vivir una vida feminista
}

Sara Ahmed (2017) "Conclusión 1. Un kit de supervivencia aguafiestas" y “Conclusión 2. Un manifiesto aguafiestas”. En Living a Feminist Life, Durham, Duke University Press, pp. 235-268. ${ }^{1}$

\section{Sara Ahmed}

Escritora feminista y académica independiente.

\section{( Nayla Luz Vacarezza (trad.)}

Doctora en Ciencias Sociales (UBA) e investigadora Conicet/Instituto de Investigaciones Gino Germani, Facultad de Ciencias Sociales, UBA.

\section{CONCLUSIÓN 1. UN KIT DE SUPERVIVENCIA AGUAFIESTAS $^{2}$}

Convertirse en una aguafiestas puede sentirse, a veces, como hacerte la vida más difícil de lo necesario. He escuchado esta opinión expresada como algo amable: como diciendo, dejá de darte cuenta de las exclusiones y tu carga se verá alivianada. Se da a entender que si no luchás contra algo te recompensarán con una mayor proximidad a eso. Podría ser que te incluyan si dejaras de hablar de las exclusiones. A veces esa opinión es expresada de una manera menos amable: la desaprobación puede ser expresada con miradas de costado, con suspiros, con ojos en blanco; dejá de luchar, adaptate, aceptá. Y puede ser que sientas esto: como si darte cuenta de ciertas cosas significara hacerte las cosas más difíciles.

Pero las experiencias que tenemos no se limitan a desgastarnos; esas experiencias también nos dan recursos. Lo que aprendemos de estas experiencias puede ser cómo sobrevivimos a estas experiencias. Hacia el final del

1 Versión original: Ahmed, Sara, "Conclusion1. A Killjoy Survival Kit” y "Conclusion 2. A Killjoy Manifesto”, en Living a Feminist Life, Durham, Duke University Press, 2017, pp. 235-268. Todos los derechos pertenecen a Duke University Press. Este material no se distribuye bajo licencia Creative Commons (CC-BY-NC 4.o). Todo tipo de uso debe ser solicitado a Duke University Press. Publicado con permiso de la editorial. Traducción al español de Nayla Luz Vacarezza.

2 N. de la T.: Aguafiestas es la traducción elegida para la palabra inglesa killjoy. Podríamos decir que, en inglés, esta palabra se compone de dos partes: kill y joy. La primera palabra significa "matar" y la segunda "alegría" por lo que, en una traducción literal, killjoy sería alguien que "mata la alegría”. En esta traducción se usa el género femenino gramatical para la figura de la feminista aguafiestas porque ese es el género gramatical utilizado por la autora. Sin embargo, cabe aclarar, que Sara Ahmed escribe desde una posición explícitamente queer y contraria a cualquier posición excluyente dentro de los feminismos, por lo cual, el uso del femenino gramatical no debería leerse como una posición esencialista que restringe el uso del femenino o de la figura de la aguafiestas a una configuración corporal o identitaria determinada. A lo largo del texto se utiliza asimismo la " $x$ " como desinencia de género inclusiva y otros giros que permiten evitar las declinaciones de género. El uso del femenino, junto con el de la " $x$ " y de los recursos con los que cuenta el castellano para no declinar el género forman parte de un esfuerzo en la traducción para tensionar el sesgo androcéntrico del castellano y el habitual uso universalizante del género masculino gramatical. La segunda persona del singular se traduce utilizando los modos del castellano rioplatense. 
capítulo 9, planteé la cuestión de la supervivencia. Aquí empiezo por la supervivencia; es el comienzo de algo. Supervivencia aquí se refiere no solo a seguir viviendo, sino a seguir adelante en el profundo sentido de seguir adelante con los propios compromisos. Como sugiere Alexis Pauline Gumbs, necesitamos una "redefinición robusta y transformadora de la supervivencia" (2010: 17). La supervivencia puede tratarse también de mantener vivas las propias esperanzas; de aferrarse a los proyectos que, justamente, son proyectos porque todavía no se han realizado. Puede que tengas que usar la obstinación para aferrarte a algo cuando te piden que lo abandones; que lo dejes ir. La supervivencia puede ser, entonces, lo que hacemos por otras personas, con otras personas. Nos necesitamos mutuamente para sobrevivir; necesitamos ser parte de la supervivencia de lxs otrxs.

Comprometerse con una vida feminista significa que no podemos no hacer este trabajo; que no podemos no luchar por esta causa, sea lo que sea que cause y, entonces, tenemos que encontrar la manera de compartir los costos de este trabajo. La supervivencia, por lo tanto, se convierte en un proyecto feminista compartido. Así que esta caja de herramientas contiene mis cosas personales, lo que he acumulado con el tiempo; cosas que sé que necesito hacer y que sé que necesito tener cerca para seguir adelante. Vamos a acumular cosas diferentes, vamos a tener nuestras propias cosas; podemos echar una mirada en los kits ajenos y encontrar ahí la historia feminista de alguien más. Pero creo que lo importante del kit no es solo lo que ponemos dentro; sino el kit en sí mismo, tener un lugar donde depositar esas cosas que son necesarias para tu supervivencia. El feminismo es un kit de supervivencia aguafiestas.

Podríamos pensar en este kit de supervivencia feminista como una forma de autocuidado feminista. Sin embargo, pensar en el kit de supervivencia feminista como una forma de autocuidado podría parecer parte de una agenda neoliberal, una manera de hacer que el feminismo se trate de la resiliencia de las personas individuales. ${ }^{3}$ Discutí el problema de la resiliencia en el capítulo 7, y la manera en que se nos pide que seamos resilientes para que podamos aguantar más (más opresión, más presión, más trabajo). Pero este es nuestro problema: el feminismo necesita feministas para sobrevivir. Puede ser que sigamos necesitando aguantar la presión a la que nos someten cuando nos negamos a aguantar más, cuando nos negamos a soportar un mundo.

El feminismo necesita feministas para sobrevivir: mi kit de supervivencia aguafiestas se ensambla en torno a esta frase. Es una frase feminista. Dicho al revés también es muy cierto: quienes son feministas necesitan al feminismo para sobrevivir. El feminismo necesita de quienes vivimos la vida como feministas para sobrevivir; nuestra vida se convierte en una supervivencia feminista. Pero el feminismo necesita sobrevivir; y nuestra vida se convierte en una supervivencia del feminismo en este otro sentido. El feminismo nos necesita; el feminismo necesita no solo que sobrevivamos, sino también que dediquemos nuestras vidas a la supervivencia del feminismo. Este libro ha sido la expresión de mi voluntad de hacer este compromiso. Quienes son feministas necesitan al feminismo para sobrevivir.

Audre Lorde, en su extraordinario poema "A Litany of Survival", se dirige a quienes "no estaban destinadas a sobrevivir", a aquellas para quienes la supervivencia requiere de creatividad y trabajo; aquellas para las que sobrevivir es políticamente ambicioso. Déjenme compartir algunas líneas de ese poema:

3 Para una discusión acerca de cómo la crítica del neoliberalismo puede ser usada de formas conservadoras (e, incluso, de maneras que justifican una retirada con respecto a los compromisos con la igualdad), ver la publicación en mi blog: "Selfcare as Warfare", feministkilljoys.com, 25 de agosto de 2014, disponible en: http://feministkilljoys.com/2014/o8/25/selfcare-as-warfare/. Ver también: “Against Students", feministkilljoys.com, 25 de junio de 2015, disponible en: http://feministkilljoys. com/2015/06/25/against-students/ 


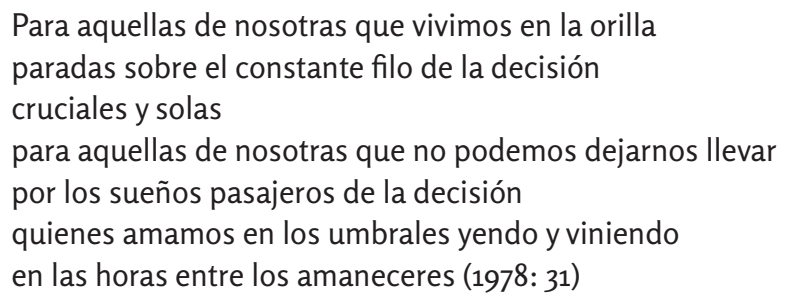

Aquí, a través del arte de la descripción de la luz, Lorde evoca a "aquellas de nosotras" que viven y aman en los bordes de las experiencias sociales, en umbrales, en las sombras, aquellas de nosotras que caen como caen las sombras, las caídas, aquellas para quienes estar completamente a la vista puede ser peligroso, aquellas para quienes la supervivencia puede requerir no salir a plena luz del día.

\section{La supervivencia puede ser una protesta.}

Y entonces: la forma en que nos cuidamos se convierte en una expresión de cuidado feminista. Audre Lorde, como podríamos esperar, nos ayuda a diferenciar la supervivencia de otros estilos de política orientada al yo. Lorde escribe, "Cuidarme a mí misma no es autoindulgencia, es autopreservación, y es un acto de lucha política" (1988: 131). Esta es una frase revolucionaria, extraordinaria. Es una frase muy querida y muy citada. Es una flecha cuya punta adquiere el filo de su propia dirección. Pertenece al epílogo de A Burst of Light, un texto que es tan profundo, tan conmovedor, que nunca deja de enseñarme, muchas veces dejándome deshecha, fuera de mí (y esta es la razón por la cual, como leerán más adelante, este libro está en mi kit de supervivencia). Ese texto está hecho de fragmentos de notas reunidas cuando Audre Lorde se entera de que tiene cáncer de hígado, que su muerte solo puede ser retardada, y comienza a sentir el diagnóstico en sus huesos. La expresión a burst of light ("un estallido de luz") es usada cuando ella comienza a sentir la fragilidad de la situación de su cuerpo: "ese saber ineludible, en los huesos, de mi propia limitación física” (Lorde, 1988: 121).

A Burst of Light es un relato de cómo la lucha por sobrevivir es una lucha vital y una lucha política. Una sentencia de muerte no es solo lo que Jasbir Puar (2009) ha llamado "tiempo de prognosis": no es (o no es solamente) experimentar tu muerte como algo inminente. Cuando se supone que no tenés que vivir, tal como sos, en donde estás, o con quien estás, entonces sobrevivir es una acción radical; un rechazo a no existir hasta el final; un rechazo a no existir hasta que no existas. Tenemos que elaborar formas de sobrevivir en un sistema que decide que la vida de algunas personas requiere de la muerte o de la eliminación de otras. A veces: sobrevivir en un sistema es sobrevivir a un sistema. Algunas de nosotras tenemos que ser creativas, sugiere Audre Lorde, para sobrevivir.

\section{Otrxs: no tanto.}

Cuando todo un mundo está organizado para promover tu supervivencia - desde la salud hasta la educación, los muros preparados para que tu casa esté segura y los caminos que facilitan tu paso- no tenés que ser muy creativx para sobrevivir. No necesitás que te vean como benificiarix del estado de bienestar porque el mundo ha promovido tu bienestar. Los beneficios que recibes te son otorgados como derechos, quizás incluso como derechos de nacimiento. Esta es la razón por la cual describo el privilegio como una zona de protección; son todos los apoyos que tenés a tu disposición cuando perdés algo. El privilegio no significa que seamos invulnerables: las cosas pasan; y pueden ser una mierda. Pero el privilegio puede reducir los costos de la vulnerabilidad; porque tenés más probabilidades de que te cuiden. 
El capitalismo racial es un sistema de salud: una distribución drásticamente desigual de las vulnerabilidades del cuerpo. Ruth Wilson Gilmore describe así el racismo: "la producción y explotación de la vulnerabilidad a la muerte prematura de ciertos grupos, sancionada por el estado o de manera extralegal" (2007: 28). Ser pobre, ser una persona negra, ser una persona de color pone tu vida en peligro. Tu salud está en riesgo cuando no tenés los recursos externos para dar soporte a una vida y a todas sus contingencias. $Y$ entonces, por supuesto, te consideran responsable por tu estado de salud frágil y por tu fracaso en la tarea de cuidarte mejor. Cuando te referís a las estructuras, a los sistemas, a las relaciones de poder, a los muros, se considera que estás haciendo responsables a las demás personas de tu fracaso para salir de esta situación. "Deberías haberte esforzado más". Oh, la violencia y la petulancia de esa frase, de esa sentencia.

Un sistema de salud es también un sistema de apoyo. Cuanto mayor es tu precariedad, mayor es el apoyo que necesitás. Cuanto mayor es tu precariedad, menor apoyo tenés. Cuando decimos que algo es precario, usualmente queremos decir que está en una posición precaria: si el jarrón en la repisa fuera empujado, solo un poco, un poquito, se vendría abajo. ${ }^{4}$ Esa posición - la de vivir en el borde - es lo que se generaliza cuando hablamos de poblaciones precarias (Butler, 2015). Vivir en el borde: una vida vivida como un frágil hilo que se sigue desenrollando; cuando la vida se convierte en un esfuerzo de aferrarse a eso que se sigue desenrollando.

Cuando pienso en esto, pienso en cómo esa fragilidad que es un esfuerzo para aferrarse a algo podría convertirse en un gesto más rebelde; cómo la fragilidad puede ser militancia. A lo largo de todo A Burst of Light, Audre Lorde compara su experiencia de estar luchando contra el cáncer (y ella quiere usar este lenguaje militarista; ella quiere describir esta situación como una guerra) con la experiencia de luchar contra el racismo antinegro. La comparación es efectiva, nos muestra cómo el racismo puede ser un ataque a las células del cuerpo, de su cuerpo, su cuerpo negro, un ataque al sistema inmunitario del cuerpo; la manera en que tu propio cuerpo experimenta lo que está fuera de él como si estuviera dentro de él; la muerte desde afuera hacia adentro. Un mundo que está en tu contra puede experimentarse como tu cuerpo volviéndose en tu contra. Esta es la razón por la que, para Lorde, cuidarse no es autoindulgencia sino autopreservación. Luchar por la vida es una rebelión cuando te han dado una misión de muerte.

En la afirmación de que cuidarse no es autoindulgencia podemos oír, en consecuencia, una defensa. Audre Lorde está defendiendo el autocuidado. ¿De qué? ¿De quién? De quienes, podría sospecharse, desestiman el autocuidado porque lo entienden como autoindulgencia. La autoindulgencia tiende a entenderse como ser blandengue, pero también significa ser complaciente con los propios deseos. Recientemente, he escuchado que mucho trabajo feminista se desestima en estos términos. El feminismo: demasiado blando, demasiado seguro, demasiado enfocado en políticas de la identidad o en el sufrimiento individual. El activismo feminista estudiantil, en particular, ha sido desdeñado de esta forma: espacios seguros, advertencias de detonantes (trigger warnings), 5 autocuidado, todas estas estrategias han sido tomadas como evidencia de

4 No podemos hacer nuestras distinciones lo suficientemente claras aquí (las distinciones claras no nos aproximan a los mundos desordenados), pero vale la pena pensar acerca de la relación entre fragilidad, que es la palabra que estuve usando, y precariedad, que es la palabra más usada en las conversaciones académicas. Fragilidad parece ser usada para indicar la cualidad de algo que es material o físico, mientras que es más probable que precariedad sea usada para indicar una posición: entonces, un jarrón sería frágil porque está hecho de porcelana, pero sería precario porque está en un borde. Creo que la razón por la que elegí trabajar con el término fragilidad en lugar de precariedad es que tiendo a trabajar con palabras que tienen un cierto tipo de resonancia con la vida cotidiana porque tienden a ser usadas para indicar una cualidad: de un sentimiento (sentirse frágil) o de un objeto o una persona (que es frágil).

5 N. de la T.: Trigger warning, en inglés, es un aviso que sirve para alertar al público del material sensible que un libro, artículo, imagen, película o cualquier otro producto cultural pudiera tener. Se coloca 
que el activismo estudiantil se compone de personas son mimadas y débiles. Una cosa sé por trabajar en universidades: los movimientos estudiantiles pueden estar enseñándonos cómo prestar atención a la fragilidad, a las historias que hacen que algunas personas sean más frágiles que otras, y eso puede ser un motivo para la militancia.

Y, sin embargo, Audre Lorde podría ser leída como una crítica del autocuidado. Después de todo, ella nos proporcionó una intensa crítica acerca de cómo se distrae la atención de las desigualdades estructurales atribuyendo la responsabilidad a las personas individuales (a quienes se les asigna la capacidad de superar las estructuras y se supone que fracasan cuando no las superan). Su trabajo explora cómo cuidarse puede convertirse en una técnica de gobierno: el deber de cuidarse a menudo ya está escrito como el deber de preocuparse por la propia felicidad. En The CancerJournals, Lorde muestra cómo convertir nuestra propia felicidad en nuestra primera responsabilidad puede ser el modo en que le damos la espalda a la injusticia. Lorde pregunta, “¿Estaba yo realmente luchando contra la propagación de la radiación, el racismo, la matanza de mujeres, la invasión química en nuestra comida, la contaminación de nuestro medio ambiente y el abuso y la destrucción psíquica de las personas jóvenes, simplemente para evitar lidiar con mi primera y más importante responsabilidad que es ser feliz?" (1997: 76). Audre Lorde nos ha dado la respuesta a su pregunta.

Tenemos algo sobre lo cual trabajar aquí. Audre Lorde escribe persuasivamente sobre cómo el autocuidado puede apartarte de compromisos con ciertas formas de lucha política. Y, aun así, en A Burst of Light (1988), ella defiende el autocuidado como algo que no tiene que ver con la autoindulgencia sino con la autopreservación. Ella está elaborando una distinción. Ella está afilando una herramienta. Esta forma de autocuidado no es preocuparse por la propia felicidad. Se trata de encontrar maneras de existir en un mundo que hace difícil la propia existencia. Esta es la razón, este es el cómo: quienes no tienen que luchar para sobrevivir pueden, muy fácil y rápidamente, desestimar a quienes prestan atención a su supervivencia por ser autoindulgentes. Esas personas no precisan cuidar de sí mismas, porque el mundo lo hace por ellas.

Para aquellas personas que tienen que insistir en que importan para importar, el autocuidado es un asunto de combate. Podemos pensar aquí sobre \#BlackLivesMatter (\#LasVidasNegrasImportan), un movimiento con un hashtag; un hashtag puede ser un chasquido o una ruptura (snap); un movimiento iniciado por feministas negras y activistas queer, Alicia Garza, Patrisse Cullors, y Opal Tometi, para protestar contra el modo en que las vidas negras no importan, contra las muertes negras que no son lamentadas, contra las injusticias hacia las personas negras que no son reconocidas. Importar, para algunas personas, requiere e implica agencia colectiva: "Black Lives Matter afirma las vidas de las personas queer y trans negras, las personas discapacitadas, las personas negras indocumentadas, las personas con antecedentes, las mujeres y todas las vidas negras en todo el espectro del género". 6 Tenés que afirmar que algunas vidas importan cuando el mundo está dedicado a decir que no importan.

La protesta puede ser un modo de autocuidado y de cuidado hacia las demás personas: un rechazo a no importar. El autocuidado también pueden ser esos modos ordinarios en que nos cuidamos mutuamente porque los costos de protestar se hacen muy altos, del mismo modo que los costos que llevan a la protesta siguen siendo muy altos. Al dirigir nuestro cuidado hacia nosotrxs mismxs estamos quitando cuidado a ciertos objetos apropiados; estamos dejando de cuidar a quienes se supone que deberíamos esta advertencia en ciertos contenidos con la intención de evitar reacciones negativas tales como ataques de pánico, ansiedad y otras formas de sufrimiento. Los trigger warnings son una estrategia política de cuidado surgida en los movimientos feministas, LGBT, antiracistas y de diversidad corporal. Se crearon para ayudar a que las personas puedan seleccionar los contenidos que desean o no ver y han generado numerosas polémicas.

6 Ver Black Lives Matter, “About \#BlackLivesMatter”. Disponible en: <https://blacklivesmatter.com>. 
cuidar; estamos descuidando a quienes se supone que deberíamos cuidar; estamos descuidando a los cuerpos que se supone que vale la pena cuidar. Esta es la razón por la cual en el trabajo queer, feminista y antirracista el autocuidado está relacionado con la creación de comunidad, comunidades frágiles, como exploré en la parte III de este libro, ensambladas en la experiencia de ser despedazadas. Nos reunimos a través de un trabajo ordinario, cotidiano y, a menudo, arduo de cuidarnos; de cuidarnos mutuamente.

Necesitamos de dónde agarrarnos cuando perdemos de dónde agarrarnos. Un kit de supervivencia aguafiestas es una forma de encontrar de dónde agarrarnos en el momento en que perdemos agarre, cuando las cosas se van de nuestras manos; una manera de aferrarse cuando la posibilidad que querías alcanzar parece escaparse. Feministas aguafiestas: incluso cuando las cosas se van de las manos, cuando nos salimos de control, necesitamos tener de dónde agarrarnos.

\section{ARTÍCULO 1. Libros}

Necesitás tener tus libros feministas favoritos a mano; tus libros feministas tienen que estar a mano y ser útiles. Necesitás llevarlos con vos; tenerlos con vos. Las palabras te pueden levantar cuando estás de bajón. Y tomá nota de esto: a menudo los libros nombran el problema de una manera que nos ayuda a manejar el problema. Los libros feministas más zarpados tienen una agencia especial, una agencia propia. Con ellos me siento zarpada.

Los libros que están en mi caja de herramientas son Sister Outsider A Burst of Light, Zami y The Cancer Journals de Audre Lorde; Feminist Theory y Talking Back de bell hooks; The Politics of Reality de Marilyn Frye; Gender Trouble Bodies that Matter y Precarious Life de Judith Butler; Mrs. Dalloway de Virginia Woolf; The Mill on the Floss de George Elliot; Rubyfruit Jungle de Rita Mae Brown. Sí, ya sé que esta lista tiene muchos libros de Audre Lorde y de Judith Butler. Sus palabras me llegan. Sus palabras me enseñan.

Ellos van a dondequiera que yo vaya.

\section{ARTÍ́CULO 2. Cosas}

Una vida feminista también está rodeada de cosas. Vivir una vida feminista crea cosas feministas. Tenemos inclinaciones; puede que seamos feministas que almacenan compulsivamente cosas, que guardan cada pequeño póster, cada prendedor, cada trozo de papel de una reunión; o puede que no. Pero piensen cómo una costumbre hace cosas (las fotografías de los casamientos, los signos de una vida reproductiva que se pueden juntar como un peso en las paredes). Por nuestra parte también necesitamos tener cosas; cosas que se juntan a nuestro alrededor, recordatorios de una vida feminista, incluso objetos felices, recordatorios de conexiones, de luchas compartidas, de vidas compartidas. Puede ser que tengamos más o menos cosas, pero cada feminista necesita sus cosas.

Rodeate de feminismo. En una conversación con Gloria Steinem, bell hooks describe cómo ella se rodeó de sus objetos preciados, de objetos feministas, al punto de que son las primeras cosas que ve cuando se despierta. ${ }^{7}$ Pensá en esto: creás un horizonte

7 La conversación se encuentra en: NewSchool, "bell hooks and Gloria Steinem at Eugene Lang College", YouTube, 8 de octubre de 2014. Disponible en: <https://www.youtube.com/watch?v=tkzOFvfWRn4/>. 
feminista alrededor tuyo, la calidez de los recuerdos, el feminismo como productor de memoria. El feminismo también deja cosas atrás. Las cosas también pueden servir para manejar lo que enfrentás: te recuerdan por qué estás haciendo lo que estás haciendo. Las cosas son recordatorios.

Nuestra política feminista hace cosas y también rompe cosas.

\section{ARTÍCULO 3. Herramientas}

Un kit de supervivencia es también una caja de herramientas feminista. ¿Cuáles son tus herramientas feministas? Las mías incluyen una lapicera y un teclado, una mesa; las cosas a mi alrededor que me permiten seguir escribiendo, seguir transmitiendo mis palabras hacia afuera. Tal vez un kit de supervivencia sea también una caja de herramientas. Necesitamos tener cosas para hacer cosas; cuántas más cosas enfrenta una aguafiestas, más herramientas necesita. Tal vez ella usa la computadora para escribir un blog. Una herramienta: un medio para un fin aguafiestas. El blog se convierte en una herramienta; es el modo en que ella puede extender su alcance; es el modo en que ella puede encontrar una comunidad de aguafiestas. Un fin feminista es a menudo un nuevo medio. Cuánto más difícil es alcanzar nuestros fines, más necesitamos nuevos medios a nuestra disposición. Necesitamos diversificar nuestras herramientas, expandir nuestro alcance; necesitamos tener más y más creatividad, porque a menudo cuando hacemos una cosa nos bloqueamos. Ella tiene que seguir adelante cuando se bloquea; ella se puede levantar levantando otra cosa, quizás algo que encuentre cerca. Por supuesto, entonces, una feminista aguafiestas se aproxima a las cosas como cosas potencialmente útiles, como medios para sus propios fines. Ella tiene un uso para las cosas. Puede ser que ella no use las cosas como se supone que tiene que usarlas. Puede ser que retuerce (queer) el uso o encuentre un uso retorcido (queer) para las cosas. Su kit de supervivencia aguafiestas, para cumplir con el propósito al cual está destinado, se convertirá, él mismo, en otra cosa útil. Pero si le pasás el kit de supervivencia a otra persona, puede ser que no sea tan útil. De hecho: un kit de supervivencia aguafiestas puede ser considerado como peligroso para la salud y la seguridad de otras personas. Es más: un kit de supervivencia aguafiestas puede ser considerado por otras personas como algo completamente inútil.

Una herramienta feminista es afilada; necesitamos seguir afilando nuestras herramientas. Cuando hablamos, a menudo se nos escucha como mordaces, nuestra voz se escucha como una voz afilada. Escuchala: chillona, estridente, la voz aguafiestas. Una voz puede ser una herramienta. Y, sin embargo, algo afilado puede volverse contundente. Una vez, una persona convirtió la contundencia en un insulto cuando me describió "como la herramienta no más afilada en la casa [del ser]". Convierto el insulto en un anhelo obstinado: dejar en claro cuestiones feministas requiere estar dispuesta a ser contundente. Mi política de citas en este libro es un buen ejemplo de esto. ${ }^{8}$

En el capítulo anterior describí al feminismo lésbico como una carpintería obstinada. Porque, sí, necesitamos feministas que se dediquen a la carpintería, feministas que se dediquen a la construcción; necesitamos hacer edificios feministas sin usar las herramientas del amo, como dice Audre Lorde, de la manera más obstinada, proclamando inquebrantablemente que las herramientas del amo nunca desmantelarán la casa del amo. Es posible que necesitemos herramientas feministas para hacer herramientas

8 N. de la T.: En Living a Feminist Life, Sara Ahmed adopta una "estricta política de citación" según la cual no cita a ningún hombre blanco. También, excluye explícitamente de su sistema de referencias bibliográficas a las autodenominadas feministas radicales que tienen posiciones trans excluyentes. 
feministas. Podemos convertirnos en herramientas; podemos convertirnos en ladrillos, ladrillos feministas.

Por supuesto, a veces una feminista tiene que hacer huelga. Hacer huelga significa dejar tus herramientas, rechazar el trabajo de trabajar con ellas. Una feminista a veces se niega a trabajar cuando las condiciones de trabajo son injustas. Una herramienta es lo que ella puede dejar cuando está en huelga.

\section{ARTÍ́CULO 4. Tiempo}

¿Se aceleró tu corazón cuando leíste ese correo electrónico? ¿Se aceleraron tus dedos cuando tecleaste esa respuesta como si estuvieran impulsados por la fuerza de tu furia? ¿Tenés la sensación de que te está pasando esto, de que te atrapa lo que sucede, y te estremecés por lo que pasa? Sea lo que sea que decidas, sea que mandás algo, o no lo hacés, decís algo, o no lo decís, pará, respirá; tomate algo de tiempo. Desacelerá. Fruncí el ceño. Puede ser que lo mandes igual, pero te va a alegrar haberte dado tiempo para decidir; te vas a alegrar.

El tiempo también significa tener tiempo de descanso. Incluso si has aceptado de buena gana la tarea de ser aguafiestas, sos más que esa tarea. Tomate descansos; hacé otras cosas, con cosas. El tiempo de descanso puede ser necesario para darle tiempo a algo.

Tener tiempo de descanso de ser aguafiestas es necesario para alguien aguafiestas si va a persistir como aguafiestas. Ser aguafiestas no es todo lo que sos, y si te dejás consumir por ella, ella puede absorber mucha energía y voluntad. Volvé a ella y ella volverá a vos: vos lo harás, ella lo hará.

\section{ARTÍCULO 5. Vida}

La vida tiene tantas cosas, como sabemos, cosas que son ordinarias o que simplemente están ahí, cosas hermosas, para amar; esas cosas que van y vienen; esas cosas que son tanto más valiosas porque son frágiles. Ser aguafiestas es demasiado absorbente, si te aleja de los mundos en los que estás; del amanecer y la caída del sol, del modo en que los árboles se inclinan, de la sonrisa de unx amigx cuando compartís una broma, del agua fresca y fría; de la sensación del mar como inmersión; de los aromas familiares de las especias cocinándose.

Dos veces en mi vida un animal vino a mi vida y la hizo sentir más viable, hizo vibrar mi vida con posibilidades: cuando tenía doce años, fue Mulka, un caballo que estuvo conmigo por casi treinta años (lo mencioné en el capítulo 2), estuvo siempre ahí incluso cuando vivimos en continentes distintos. Mulka me salvó la vida, de eso estoy segura, me ayudó a encontrar otro camino cuando me estaba precipitando hacia un destino miserable. Él trajo consigo un mundo, un mundo de gente aficionada a los caballos, en las sierras de Adelaide, un mundo lejos de la escuela y de la familia. Trajo consigo a Yvonne y Meredith Johnson, quienes al cuidarlo cuando yo estuve lejos, cuidaron de mí. Y luego vino Poppy, nuestra cachorra, que llegó a mi vida cuando estaba escribiendo este libro. Es la primera vez que comparto la vida con unx perrx. Ella hace que todo sea mejor. Ella trajo tantas cosas consigo, tanta determinación en la tarea de ser ella misma; una presencia saltona que me mantiene en el presente. 
Ella entró contoneándose en mis afectos. También entró contoneándose en este kit de supervivencia. Se va a salir contoneándose otra vez. De eso, también, estoy segura.

Sobrevivir como se es: estar con Mulka; estar con Poppy; estar en un presente; estar en un mundo; estar viva con un mundo.

La vida importa; somos aguafiestas porque la vida importa; y la vida puede ser eso por lo que las aguafiestas están luchando; la vida requiere que le dediquemos tiempo a vivir, a estar vivas, a ser arrojadas al mundo junto con otras personas. Necesitamos proyectarnos por cómo otras personas se proyectan. Necesitamos desconcertarnos por lo que es desconcertante. Necesitamos dejar que entre la vida, con todas sus contingencias. Pienso en esto como dejar la puerta abierta al azar. Y, como sugerí en el capítulo 8, afirmar el azar es un tipo de ruptura o de chasquido (snap); rompemos un vínculo que decide en nuestro lugar cuál es la forma que debe tener una vida para ser considerada una buena vida. Pero eso no significa que rompamos nuestro vínculo con la vida. Rompemos un vínculo por la vida. Creemos en la vida mucho más cuando tenemos que luchar por la vida, sea lo que sea que tengamos que romper, porque tenemos que luchar para existir o luchar para transformar una existencia.

Involucrarse en un proyecto de vida es algo afirmativo. Quienes somos consideradas aguafiestas lo sabemos muy bien; sí, se nos considera negativas y se nos asigna esa tarea, pero en nuestro deseo de aceptar esa tarea afirmamos algo. Puede ser que tengamos distintas palabras, o nombres, para lo que afirmamos.

\section{ARTÍCULO 6. Autorizaciones}

Hay tantas cosas por hacer. Tengo en mi kit de supervivencia aguafiestas algunas autorizaciones para dar un paso atrás cuando es demasiado. Observé en el capítulo 7 que podés aprender a elegir tus batallas sabiamente, pero que las batallas también pueden elegirte a vos. No siempre sabés cuándo vas a poder usar tus autorizaciones, ni cuando las vas a usar efectivamente, incluso si decidiste darte esos permisos. Pero el mero hecho de tenerlas, como una forma de darte permiso para salir de una situación, puede hacer que la situación sea más llevadera. Podés irte, podés afligirte.

Ya he descrito cómo fue que dejé mi posición académica. Renuncié porque me di permiso para renunciar. Esa no es la única razón. Pero tenés que poder dejar una situación, ya sea que dejes o no la situación finalmente. Para poder irse es necesario contar con recursos materiales, pero también es necesario un acto de voluntad, no disponerse a hacer algo si ese algo pone en riesgo tu capacidad para ser algo.

También tengo en mi kit algunas justificaciones por enfermedad. ¿Intuís que un evento o una reunión puede ponerte en riesgo? ¿Sentís que te vas a alterar y no vas a poder hacer nada? Bueno, poné algunas justificaciones por enfermedad en tu kit. Usalas con moderación, pero dado que puede enfermarnos el mero hecho de que anticipamos que podemos enfermarnos, estas justificaciones expresan una verdad tanto política como personal. Por supuesto, esto no quiere decir que lo que anticipamos va a suceder; claro que no. Pero, a veces, solo a veces, no queremos correr el riesgo. Sé obstinada cuando no querés algo. Siempre. 


\section{ARTÍCULO 7. Otrxs aguafiestas}

Creo que otrxs aguafiestxs son una parte esencial de mi kit de supervivencia aguafiestas. Ya sé que puede sonar extraño poner a otras personas en un espacio que designaste como tu espacio (en una bolsa, sigo pensando en bolsas; ¿cómo podemos respirar en una bolsa?). Pero no puedo pensar en ser aguafiestas sin la compañía de otrxs aguafiestas. No se trata de una cuestión de identidad, no se trata de dar por hecha una comunidad de aguafiestas (discutí el problema que supone hacer esta suposición). Más bien, se trata de la experiencia de contar con otras personas que reconocen las dinámicas porque ya han estado ahí, en ese lugar, ese lugar difícil. Esto no quiere decir que no podemos convertirnos en aguafiestas para otrxs aguafiestas. Podemos y lo hacemos. Y esa es otra razón para que otrxs aguafiestas tengan que ser parte de nuestro kit de supervivencia. Nos ayudan a reconocer cómo también podemos ser el problema; también podemos ser parte del borramiento de las contribuciones y las posibilidades de lxs demás.

Aprendí esta lección recientemente cuando mi participación en una conversación sobre feminismos negros británicos fue cuestionada por mujeres negras que consideraron que yo participaba de su borramiento de espacios públicos y discusiones. Respondí muy rápidamente y me puse a la defensiva, escuché sus voces como parte del mismo coro de lo que llamaría críticas cuestionables que aseguran que las mujeres marrones (brown women) obtienen ventajas al tomar espacios que no les pertenecen, y que utilizan la narrativa familiar de que las mujeres de color usan a la diversidad para su ascenso profesional. Escuché como una aguafiestas. Y eso me impidió escuchar a las aguafiestas que se estaban poniendo en el camino de lo que yo pensaba que era mi sustento: el feminismo negro británico como mi comunidad intelectual. Estar cerca de otras aguafiestas, entonces, no significa estar del mismo lado. Es el modo en que podemos demandar más de nuestra parte; es como podemos ser y estar alertas.

Nuestro enfado puede y debe dirigirse a nosotras mismas. A veces entendemos mal las cosas. Yo lo hice. Y lo hago.

\section{ARTÍCULO 8. Humor}

Una parienta cercana de la figura de la feminista aguafiestas es la figura de la feminista sin humor: la que no puede o no va a entender la broma; la que es infeliz. ¡Oh, la proximidad del parentesco! Por supuesto, nos negamos a reírnos de chistes sexistas. Nos negamos a reír cuando los chistes no son divertidos. Considero que este punto es algo tan vital que constituye el cuarto de los diez principios de mi manifiesto aguafiestas. Pero sí, nos reímos; y la risa feminista pueda alivianar nuestras cargas. De hecho, nos reímos seguido cuando reconocemos el absurdo compartido que es este mundo; o cuando reconocemos este mundo. A veces nos reímos de los puntos que quedan abiertos, de las arterias sangrantes de nuestro saber institucional. A veces nos reímos al unísono porque reconocemos que reconocemos las mismas relaciones de poder.

Lo que estoy sugiriendo aquí es: alivianar nuestras cargas es parte de la estrategia de supervivencia aguafiestas. Cuando estamos lidiando con historias pesadas, alivianar se convierte en una actividad compartida. Cuando estamos lidiando con normas que nos aprietan cada vez más cuando fracasamos en habitarlas, haciendo difícil incluso respirar, aflojar se convierte en una actividad compartida. Parte del trabajo de alivianar y de aflojar es compartir: porque el trabajo en el ámbito de la diversidad es costoso, tenemos que compartir los costos de hacer ese trabajo. 
Mis entrevistas con practicantes del ámbito de la diversidad sobre las que me basé en la parte II del libro estuvieron llenas de risas. Como esa vez que una practicante del ámbito de la diversidad contó cómo bastaba que ella tomara la palabra en reuniones para ver cómo los ojos de quienes estaban ahí se ponían en blanco, como diciendo "Oh, otra vez lo mismo". Cómo nos reímos como aguafiestas reconociendo ese momento aguafiestas. $\mathrm{O}$ esa vez que otra practicante del ámbito de la diversidad me contó que su amigx le preguntó "¿tienen relación?" frente a una foto de ella con todo el equipo de dirección (todos hombres blancos). Cómo nos reímos en ese momento que dejó expuesto cómo las instituciones trabajan como sistemas de parentesco. Puede ser un gran alivio cuando captamos con palabras una lógica que a menudo es reproducida sin ser puesta en palabras. Reconocemos que otras personas reconocieron la lógica. La risa, su repiqueteo; y nuestros cuerpos captando esa lógica, también.

No siempre nos reímos, por supuesto. A veces tenemos que dejar que todo el peso de una historia nos abata. A veces tenemos que dejarnos estar tristes. Pero, a veces, esta sensación de tristeza se puede convertir en energía, porque nos podemos reír de ella; porque nos enfrentamos con cosas que nos dan recursos para testimoniar, para exponer esas cosas, para llevarlas a la superficie, y poder reírnos de ellas.

Reírse de algo puede ser hacerlo más real, magnificarlo y, al mismo tiempo, puede reducir el poder que tiene sobre vos.

\section{ARTÍCULO 9. Sentimientos}

Nuestras emociones pueden ser un recurso; recurrimos a ellas. Ser aguafiestas es a menudo que te consideren emocional, demasiado emocional; dejás que los sentimientos entorpezcan tu juicio; dejás que tus sentimientos estorben. Tus sentimientos pueden ser un lugar de rebelión. Un corazón feminista late a destiempo; el feminismo es puro corazón.

Un profesor, colega de mi trabajo, me decía una y otra vez, y decía a las demás personas, que no entendía a la feminista aguafiestas; que ella no tenía sentido para él. Lo decía repetidamente. Explicámela. En realidad, él estaba diciendo: explicate a vos misma. Y siguió diciendo cosas como que no tenía sentido porque hay mujeres que son gerentas de alto rango. En otras palabras, él pensaba que el sentimiento feminista correcto debería ser la alegría, o incluso la gratitud, por la buena fortuna de nuestra incorporación y de nuestro progreso. Tenemos que estar dispuestas a ser percibidas como desagradecidas, a usar ese rechazo de la alegría como una forma de exponer aquello que se nos ha ordenado no expresar. En su rechazo a entender a la feminista aguafiestas, el profesor estaba sugiriendo que organizar mi propio proyecto político e intelectual en torno a ella era una deslealtad institucional, algo que potencialmente podría dañar a la institución.

Pienso en la invitación aguafiestas de Adrienne Rich (1979) a ser "desleal a la civilización". Nuestras emociones se sinceran cuando rechazamos el mandato de ser leales y alegres. No siempre sabemos cómo nos sentimos, incluso cuando sentimos algo intensamente. Poné todos esos sentimientos en tu kit. Mirá lo que hacen. Mirá el lío que provocan. Un kit de supervivencia se trata de revolver las cosas y de vivir en ese lío. 


\section{ARTÍCULO 10. Cuerpos}

Es cierto, es desgastante. Podemos desgastarnos y entristecernos. Los cuerpos necesitan ser cuidados. Los cuerpos necesitan ser nutridos y alimentados. El feminismo también puede ser pensado como una dieta; una dieta feminista es el modo en que el feminismo nos nutre. En mi kit de supervivencia aguafiestas yo tendría una bolsa de chiles frescos; tiendo a agregar chiles a la mayoría de las cosas. No estoy diciendo que los chiles sean feministas en miniatura. Pero deberías tener en tu kit lo que sea que suelas agregar a las cosas; no importa cómo adaptes las comidas a tus propios requerimientos. Si tenemos una diversidad de cuerpos, tenemos una diversidad de requerimientos.

Y este artículo se relaciona con todos los demás. Los cuerpos son la relación mediadora. Cuando no sobrevivimos, nos convertimos en un cuerpo; un cuerpo es lo que queda. Un cuerpo queda atrás. Un cuerpo es vulnerable; somos vulnerables. Un cuerpo nos dice el tiempo; los cuerpos llevan consigo las marcas de los lugares donde hemos estado. Tal vez somos esas marcas. Una aguafiestas tiene un cuerpo antes de recibir su tarea.

Los cuerpos nos hablan. Tu cuerpo puede decirte que no puede afrontar lo que le estás pidiendo; y tenés que escuchar. Tenés que escuchar a tu cuerpo. Si grita, pará. Si se queja, bajá un cambio. Escuchá. Orejas feministas: ellas también están en mi kit de supervivencia.

Mucha energía está implicada en la batalla para que tu existencia no te ponga en peligro. Pero, como observé en este libro, afirmar la figura de la aguafiestas, decir "soy ella" en una situación o en otra puede ser vigorizante; ella tiene algo, un sentido de la vitalidad, o tal vez un sentido de la rebelión y de la picardía, quizás, o incluso de atrevimiento o malicia, que puede explicar por qué y cómo las aguafiestas siguen circulando, siguen proliferando; ella parece que aparece por todas partes. Como dije en un capítulo anterior, si la tomamos, ella nos toma.

Y esa es otra razón por la cual los cuerpos deben estar en nuestro kit de supervivencia. Cuerpos que brincan, cuerpos que bailan, "cuerpos que importan", tomando prestados los términos de Butler (1993), cuerpos que se menean para crear espacio.

\section{Menearse está en mi kit de supervivencia.}

\section{Bailar, también.}

Cuerpos que bailan: con cuánta frecuencia las feministas sostuvieron que bailar es esencial para su liberación. Podríamos pensar en la famosa frase de Emma Goldman, "Si no puedo bailar, no me interesa tu revolución". O pienso en el documental sobre la supervivencia de Audre Lorde, The Berlin Years, y su secuencia final que muestra a Audre bailando, secuencia que parece capturar muy bien la generosidad de su espíritu feminista negro. Pienso en el baile de la conferencia Lesbian Lives que he disfrutado a lo largo de los años (también las charlas, pero el baile es lo que recuerdo más rápidamente). Un cuerpo feminista danzante, un cuerpo lesbiano danzante, cuerpos danzantes negros y marrones; la afirmación del modo en que habitamos los cuerpos a través del modo en que estamos con otras personas. Estamos aquí, seguimos aquí. Cualquiera puede bailar con alguien más para formar un colectivo. No digo que las aguafiestas tengan un género o un estilo específico de baile. No digo que haya un baile aguafiestas (aunque quizás, solo quizás, haya un baile aguafiestas). Quizás en su postura hay un tipo de brinco; quizás en la energía que satura su figura, ella se convierte en una asamblea. 


\section{Mirala moverse:qué movimiento.}

Y, al poner el baile en mi kit de supervivencia aguafiestas, estoy diciendo algo afirmativo. ¿Hay una contradicción aquí? Cuando estoy alegre, ¿dejo de ser aguafiestas? Bailar puede ser el modo en que abrazamos la fragilidad de ser arrojadas. Y la alegría también es parte de la supervivencia aguafiestas, sin dudas. Necesitamos fiestas para sobrevivir a la tarea de aguar fiestas; incluso podemos alegrarnos aguando la alegría de otras personas. Y esta es la parte erótica de mi kit, el tipo de erotismo del que Audre Lorde habló con tanta elocuencia; la feminista aguafiestas se va calentando a medida que la van acusando; ella es una figura erótica. Puede ser que ella haya llegado a ser como una negación o la negación misma, pero esa negación vibra con deseo; un deseo de más para la vida, más deseo; un deseo de más. Quienes son feministas aguafiestas tienden a desparramarse por todos lados. ¿Qué desparramo!

\section{Feministas aguafiestas: un recipiente agujereado.}

\section{Yentonces:}

\section{Cuidado, nos desbordamos.}

Podemos recordar otra vez el llamamiento de Shulamith Firestone (1970: 90) a un "bloqueo de sonrisas" en su manifiesto revolucionario, Dialectic of Sex. Ella quiere que dejemos de sonreír a fuerza de costumbre; algo que se ha vuelto involuntario; parar de sonreír hasta que tengamos algo que nos haga sonreír. Un boicot de sonrisas podría ser una acción colectiva; solo funcionaría si todas dejáramos de sonreir. No sonreír se convierte en una huelga feminista. Voy a volver sobre este feminismo en huelga en mi manifiesto aguafiestas. Pero noten cómo el llamado de Firestone es también un llamado para abrir lo erótico, para liberar lo erótico del hábito de la felicidad que orienta la vida hacia "un callejón de la experiencia humana angosto y difícil de encontrar" (1970: 155).

En el capítulo "El feminismo es sensacional" exploré cómo el feminismo puede consistir en cobrar vida en un mundo que te había sido vedado por el requerimiento de que vivas tu vida de cierta forma. Las cosas cobran vida cuando no son ignoradas. Entonces, es importante decir esto: necesitamos permitirnos estar tristes y enojadas; cuando la alegría y la felicidad se convierten en ideales, la tristeza se convierte muy rápidamente en un obstáculo, en la imposibilidad de tener o de aproximarse a los sentimientos correctos. La tristeza puede requerir de una autorización (ítem 6). Pero al mismo tiempo, la alegría puede ser parte del kit de supervivencia aguafiestas. Personalmente, no necesito una autorización para la alegría; en mi experiencia, la alegría es un mandato cultural incluso cuando puede ser un lugar de rebelión (la alegría colectiva de la disidencia); pero si necesitás darte permiso para estar alegre, escribite una autorización. Pienso que la alegría solo puede ser parte del kit de supervivencia aguafiestas si nos negamos a darle el estatus de una aspiración. Cuando la alegría se convierte en una aspiración, la alegría se convierte en lo que la aguafiestas tiene que aguar. Pero, incluso si la supervivencia para quienes son aguafiestas requiere de negarse a convertir la alegría (o su amiga más pesada la felicidad) en una aspiración, eso no significa que tengamos la obligación de estar tristes o infelices. Una aguafiestas no es una amarga.

Volviendo a Emma Goldman, en su libro Living My Life, ella afirma la libertad de bailar cuando le han dicho que no lo haga; ella baila y se le dice que no es el momento correcto para bailar, debido a la "muerte de un querido camarada" (2008 [1931]: 56). A medida que ella cuenta la historia, dice que un joven con cara solemne le susurró, "bailar no es propio de un agitador". En este momento, Goldman afirma el baile como 
una rebelión afectiva contra el requerimiento de estar triste; contra el requerimiento de no vivir en su cuerpo a través del alegre abandono. Esto es lo que yo llamo un momento de extrañeza afectiva. Un kit de supervivencia aguafiestas se trata también de permitir que tu cuerpo sea el sitio de una rebelión, inclusive de una rebelión contra la demanda de entregar tu cuerpo a una causa o de hacer de tu cuerpo una causa. Puede ser, también, que no bailar sea lo que un cuerpo haga; negarse a bailar cuando bailar es una exigencia, dando un paso atrás, o a un lado, parar.

\section{Y FINALMENTE: UN KIT DE SUPERVIVENCIA AGUAFIESTAS}

Armar un kit de supervivencia aguafiestas también puede ser una estrategia de supervivencia. Mi kit de supervivencia aguafiestas está en mi kit de supervivencia aguafiestas. Escribir un manifiesto feminista también puede ser una estrategia de supervivencia. Mi manifiesto, que viene a continuación, está en mi kit. Para escribir un manifiesto feminista, primero tenés que leer otros manifiestos feministas. ¡Qué alegría! Los manifiestos son "especies compañeras", para tomar prestada la descripción de uno de los manifiestos de Donna Haraway (2003). Leer manifiestos también está en mi kit de supervivencia aguafiestas. Un kit puede ser un contenedor para actividades que están en curso; proyectos que son proyectos justamente porque todavía tienen que ser realizados.

Una aguafiestas: un proyecto que proviene de una crítica de lo dado.

Hablando de proyectos:

Somos nuestros propios kits de supervivencia.

\section{CONCLUSIÓN 2. UN MANIFIESTO AGUAFIESTAS}

Un manifiesto: una declaración de principios, la declaración de un propósito. Manifiesto: declaración de la intención de alguien, o de una organización, o de un grupo. ¿Cómo se puede escribir un manifiesto en torno a una figura, la aguafiestas, $\mathrm{o}$ una actividad, aguar fiestas?

Un manifiesto: poner de manifiesto. Moynan King en su discusión sobre el Manifiesto SCUM de Valerie Solanas aborda este sentido del manifiesto que es poner de manifiesto. Ella escribe "Como un manifiesto, la intención de SCUM es poner de manifiesto, hacer perceptible, un nuevo orden de ideas" (King, 2013: s./p.). Hacer perceptible un nuevo orden de ideas es, simultáneamente, un desordenamiento de ideas; los manifiestos a menudo hacen lo que dicen de maneras sorprendentes y escandalosas dado que exponen la violencia de un orden. Un manifiesto feminista expone la violencia del orden patriarcal, la violencia de lo que llamé, en el capítulo 2, "la maquinaria del género".

Un manifiesto no solo causa perturbación, sino que tiene el objetivo de causar perturbación. Poner de manifiesto algo puede ser suficiente para causar perturbación. Esta intimidad entre manifestar y perturbar tiene implicancias sobre el modo en que escribimos un manifiesto aguafiestas. Un manifiesto aguafiestas debe estar basado en dar cuenta de lo que existe. ¿Por qué esto es importante? Porque se trata de lo que enfrentamos. Algunos de los peores abusos de poder que encontré en la academia han ocurrido cuando ciertas personas hicieron uso del principio de igualdad, como si dijeran, los límites y las reglas son jerárquicos, entonces somos "libres para hacer lo que queremos", conforme a lo cual, "libres para hacer lo que queremos" en realidad 
sigue significando "vos hacés lo que yo quiero que hagas", dado que el nosotros está hecho de un yo que tiene poder y un vos que está subordinado por virtud de su posición en una organización. Noten que "hacer lo que queremos" no solo supone la expresión de un principio de igualdad, sino que puede ser formulado como una rebelión contra las normas y autoridades institucionales (nos prevendrían de tener relaciones porque dan por supuestos límites y divisiones que nosotrxs hemos dejado de lado porque somos radicales y libres). Un manifiesto aguafiestas no puede tratarse de liberar radicales para que sigan con sus propias agendas.

Un manifiesto aguafiestas, entonces, empieza reconociendo las desigualdades existentes. Este reconocimiento se pone en acto con la figura misma de la aguafiestas: ella agua la fiesta por lo que proclama que existe. Ella tiene que seguir haciendo los mismos reclamos porque debe seguir contrarrestando las declaraciones que dicen que no existe lo que ella dice que existe. A menudo, se asume que la aguafiestas es imaginativa, que provoca lo que afirma; o, para usar mis propios términos en el capítulo 6 , a menudo se supone que ella es una constructora de muros. Si el manifiesto aguafiestas muestra cómo la negación de la desigualdad bajo la suposición de la igualdad es una técnica de poder, entonces los principios articulados de este manifiesto no pueden ser abstraídos de las declaraciones acerca de lo que existe. Un manifiesto aguafiestas es, entonces, poner de manifiesto lo que existe. En el trabajo de poner de manifiesto, hacemos un manifiesto.

Luchar por la libertad es luchar contra la opresión. Angela Davis en Blues Legacies and Black Feminism mostró cómo la articulación de anhelos insatisfechos de libertad puede también representar la libertad "en términos más inmediatos y accesibles" (1998 [1989]: 7). Es desde la opresión que se le da expresión a la libertad. Un manifiesto es imprescindible cuando se necesita una lucha para darle expresión a algo. Esta es la razón por la que el manifiesto puede ser entendido como un género aguafiestas; tenemos que decirlo porque hay cosas que no se están haciendo. Un manifiesto intenta atraer, pero no es atractivo: un manifiesto no es un texto atractivo de acuerdo con las normas y estándares existentes. No puede serlo: debe esforzarse para ser dicho. Y, aun así, un manifiesto es atractivo para quienes lo leen; un manifiesto demanda algo interpelando a alguien. Un manifiesto aguafiestas atrae $a$ aguafiestas.

A menudo los manifiestos son desagradables porque muestran la violencia que es necesaria para sostener un acuerdo. No se trata solo de que la feminista aguafiestas tenga un manifiesto. La feminista aguafiestas es un manifiesto. Ella se ensambla en torno a la violencia; ella comienza a importar, a significar algo, por cómo expone la violencia. Solo recuerden el kill ("matar") en killjoy ("aguafiestas"). Esta figura nos recuerda que el feminismo es a menudo comprendido como una forma de asesinato; llamar a terminar con el sistema que produce al "hombre" es a menudo comprendido como matar hombres. Podríamos incluso comparar la figura de la feminista asesina con la figura de la feminista aguafiestas. Lo que Valerie Solanas (2013 [1967]) hace en su manifiesto, de manera muy controversial, es literalizar la fantasía de la feminista asesina imaginando un colectivo feminista, una mentalidad, que es SCUM (Society for Cutting Up Men)..$^{9}$ No debería sorprendernos, porque uno de sus objetivos era ser un punto de inflexión y que el Manifiesto SCUM fuera leído literalmente; fue desestimado por ser literal o desestimado por su interpretación literal de que apuntaba a la eliminación de los hombres. El manifiesto funciona porque pone en acto la literalidad que permitiría su desestimación. Noté este uso de la interpretación literal para desestimar cuando trabajaba en mi blog de feminista aguafiestas. ${ }^{10}$ Por ejemplo, cuando tuiteé un enlace a una entrada de blog titulada "hombres blancos", que fue retuiteada por un

9 N. de la T.: SCUM es la sigla de Society for Cutting up Men que, en español, podría traducirse como "sociedad para despedazar a los hombres". La palabra inglesa scum, por su parte, significa "basura". 10 N. de la T.: el sitio web de Feminist Killjoys, el blog de Sara Ahmed, es: https://feministkilljoys.com/ 
hombre blanco, y que otro hombre blanco lo llamó "genosuicidio". ${ }^{11}$ Genosuicidio: el obstinado suicidio de un pueblo. Otra vez un estudiante de Goldsmiths, Bahar Mustafa, presuntamente utilizó el hashtag\#KillAllWhiteMen (\#MatenATodosLosHo mbresBlancos). ${ }^{12}$ Valerie Solanas es traída nuevamente a la vida en las redes sociales. Chasquido, ruptura. Pero, por supuesto, si este hashtag literaliza una fantasía, te encontrás literalmente con la fantasía. El hashtag se convierte en una orden; es escuchado como la planificación de un genocidio.

La figura de la feminista asesina es útil: permite que la supervivencia de los hombres se base en la eliminación del feminismo. Mucha creatividad feminista literalizó una fantasía que no originamos, incluida la película $A$ Question of Silence, analizada en los capítulos 8 y 9 , donde el hombre que es asesinado en un acto de venganza feminista representa a todos los hombres. Y de alguna manera, por supuesto, estás siendo violenta al exponer la violencia; si dejás que la violencia salga de tu pluma, que viaje a través tuyo, tenés que dejar que la violencia se desparrame, en todas las páginas. Y estás, de alguna manera, llamando a terminar con los hombres blancos porque estás llamando a terminar con la institución que crea a los hombres blancos. "Hombres blancos" es una institución, como analicé en el capítulo 6. Queremos ponerle fin. Pero, por supuesto, en otro nivel, es más difícil reubicar la figura de la feminista asesina que la figura de la feminista aguafiestas. Las feministas no están llamando a la violencia. Estamos llamando a terminar con las instituciones que promueven y naturalizan la violencia. Buena parte de la violencia que promueven las instituciones es ocultada por medio del uso del "extraño peligroso", como he analizado a lo largo de este libro: la suposición de que la violencia solo la originan extrañxs. Es porque exponemos la violencia que somos oídas como violentas, como si la violencia de la cual hablamos se originara en nosotras.

Ser aguafiestas también puede significar que te consideren como alguien que atenta contra la vida porque existe una gran intimidad entre el principio de la vida y el principio de la felicidad. Si estás en contra de la felicidad van a suponer que estás en contra de la vida. Y, como tal, hay riesgos de vida en ser aguafiestas. No porque nos designen como aguafiestas ( $\mathrm{y}$, como he sostenido, ella siempre comienza siendo designada porque la feminista aguafiestas es anunciada desde una posición de exterioridad; ella ya tiene una vida propia antes de que nos designen como tal) estaremos siempre dispuestas o preparadas para recibir esta designación que es, a la vez, una tarea.

De hecho, como exploré en la parte I, la figura de la feminista aguafiestas a menudo se presenta en situaciones de intenso dolor y dificultad: cuando estás sentada a la mesa, haciendo el trabajo de la familia, ese objeto feliz, llamémoslo así, y amenazás a ese objeto. Lo amenazás al señalar lo que ya estaba ahí, en la habitación; otra vez, no estás siendo fantasiosa. Pero qué sensación: cuando todos los sentimientos negativos que no son revelados cuando la familia funciona se depositan en quien revela que la familia no funciona. Nunca voy a olvidar ese sentimiento de desear eliminarme a mí misma de la situación que se suponía que había causado.

\section{Es un bajón; somos un bajón.}

Un manifiesto aguafiestas tiene compañía: libros que echan por tierra las cosas, libros que ponen en acto una desaprobación colectiva. The Dialectic of Sex puede ser leído como un manifiesto aguafiestas, un libro que fue muy rápidamente rechazado por 11 Sara Ahmed, “White Men”, feministkilljoys.com, 4 de noviembre de 2014. Disponible en: http:// feminiskilljoys.com/2014/11/o4/white-men/

12 Con mi agradecimiento a Bahar Mustafa por su importante trabajo político. Para una discusión más extensa de los asuntos que rodean el acoso de Bahar en medios de comunicación y redes sociales, ver Sara Ahmed, “A Campaign of Harassment”, feministkilljoys.com, 26 de mayo de 2015. Disponible en: http://feminiskilljoys.com/2015/o5/26/a-campaign-of-harassment/ 
asumir que la tecnología podría liberar a las mujeres de la biología, un libro que mostró que cuando la división sexual del trabajo estructura todo, nada va a liberar a nadie. Sarah Franklin describe cómo el "grueso del manifiesto de Firestone estaba basado en un análisis de lo que había mantenido una cierta estratificación de género en pie por milenios" (2010: 46). The Dialectic of Sex es optimista porque explica por qué la liberación es difícil de lograr. No hay dudas de que ella tiene sus momentos aguafiestas. Firestone quiere explicar por qué este sistema que no funciona sigue adelante, un sistema que ella no tiene dudas de que eventualmente nos matará a todxs. Y para explicarlo, ella se vuelca al amor, al romance, a la familia. Estas instituciones son promesas de felicidad. Una institución puede organizarse en torno a una promesa. Y se convierten en formas de organizar la vida por medio de la asunción de que la proximidad a esa forma te va a llevar ahí. Entonces, por supuesto, Shulamith Firestone al tomar esa dirección se dirige hacia la felicidad. Como ya señalé, ella describe su "acción soñada" para el movimiento de liberación de las mujeres como un boicot a la sonrisa (Firestone 1970: 90). Quizás podríamos llamar a esta acción, como lo hizo Lisa Millbank (2013), una huelga de las sonrisas, para enfatizar su carácter colectivo. Colectivamente, podríamos hacer una huelga dejando de sonreír, una colectividad hecha de acciones individuales (no sonreír se convierte en una acción cuando la sonrisa es un requerimiento para las mujeres y para quienes se supone que deben servir a otras personas a través del trabajo pago o impago) pero que requiere más que una persona individual. Una huelga de sonrisas es necesaria para proclamar nuestro desacuerdo, nuestra infelicidad, con un sistema.

\section{Debemos seguir infelices con este mundo.}

La figura de la feminista aguafiestas tiene sentido si la ubicamos en el contexto de las críticas feministas de la felicidad, algunas de las cuales analicé en el capítulo 2 -ver también Ahmed (2010)-.

La felicidad es usada para justificar las normas sociales como si fueran bienes sociales. Como Simone de Beauvoir lo describió muy astutamente, "Siempre es fácil describir como feliz una situación que se quiere imponer [a otras personas]" (1997 [1949]: 28). No aceptar quedarse en el lugar de este deseo puede ser también rechazar la felicidad que nos desean. Involucrarse en el activismo político es, entonces, involucrarse en una lucha contra la felicidad. La lucha en torno a la felicidad proporciona el horizonte en el cual hacemos demandas políticas. Heredamos este horizonte.

Una aguafiestas se convierte en un manifiesto cuando estamos dispuestas a adoptar esta figura para formar una vida, pero no como ella (analicé los riesgos de asumir que somos ella en el capítulo 7), sino en torno a ella, con su compañía. Estamos dispuestas a aguar fiestas porque el mundo que designa a esta o aquella persona, o a un grupo de personas, como aguafiestas no es el mundo del que queremos ser parte. Estar dispuesta a aguar fiestas es transformar un juicio en un proyecto. Un manifiesto: cómo un juicio se convierte en un proyecto.

Pensar en quienes son aguafiestas como manifiestos es afirmar que una política de transformación, una política que intenta causar el fin de un sistema, no es un programa de acción que puede ser separado de cómo estamos en los mundos en los que estamos. El feminismo es praxis. Ponemos en acto el mundo al que aspiramos; menos que eso no basta. El feminismo lésbico, como sostuve en el capítulo 9, es cómo organizamos nuestras vidas de manera que nuestra relación con las otras en tanto mujeres no esté mediada por nuestra relación con los varones. Una vida se convierte en un archivo de rebelión. Esta es la razón por la cual un manifiesto aguafiestas va a ser personal. Cada una de nosotras, aguafiestas, va a tener uno propio. Mi manifiesto no cancela mi historia personal. Es cómo esa historia se despliega en una acción. 
Obtenemos la energía para rebelarnos de experiencias difíciles, de ser heridas por estructuras que ni siquiera se revelan a otras personas. Obtenemos nuevos puntos de vista acerca de lo que combatimos a partir de lo que enfrentamos. Nuestros cuerpos se convierten en nuestras herramientas; nuestra rabia se convierte en enfermedad. Vomitamos; vomitamos lo que se nos pidió que traquemos. Nuestras tripas se convierten en amigas feministas cuanto más asco sentimos. Comenzamos a sentir más y más el peso de las historias; cuanto más exponemos el peso de la historia, más pasado se pone.

Estallamos en un chasquido, una ruptura. Estallamos bajo el peso; las cosas se rompen. Un manifiesto se escribe a partir de un chasquido feminista. Un manifiesto es un chasquido feminista.

Y observamos, como feministas, los problemas que causa el feminismo. Arriesgaría una suposición: el problema feminista es una extensión del problema del género (gender trouble) (Butler, 1990). Para ser más específica: el problema feminista es el problema con las mujeres. Cuando nos rehusamos a ser mujeres, en el sentido heteropatriarcal de ser para los hombres, nos convertimos en un problema, nos metemos en problemas. Una aguafiestas está dispuesta a meterse en problemas. Y esto, pienso, es lo específico de un manifiesto aguafiestas: que traemos la experiencia de lo que hemos enfrentado a nuestras declaraciones de propósito y a nuestros objetivos. Esta experiencia nos permite articular un propósito, un por, un por que trae consigo la experiencia de lo que hemos enfrentado. Un por puede ser el modo en que damos vuelta algo. Un manifiesto se trata de eso que tratamos de dar vuelta.

No tengo dudas en mi cabeza de que la feminista aguafiestas está a favor de algo; aunque, como aguafiestas, no estamos necesariamente a favor de las mismas cosas. Pero solo vas a disponerte a vivir con las consecuencias de estar en contra de lo que enfrentaste si estás a favor de algo. Una vida puede ser un manifiesto. Cuando leo algunos de los libros que están en mi kit de supervivencia, los escucho como si fueran manifiestos, como llamados a la acción; como llamados a levantar el puño. Son libros que vibran con vitalidad porque muestran cómo una vida puede ser reescrita; cómo se puede reescribir una vida, letra por letra. Un manifiesto tiene una vida, una vida propia; un manifiesto es una mano extendida. Y, si un manifiesto es una acción política, depende de cómo es recibido por otras personas. Y, quizás, una mano puede hacer más cuando no es simplemente recibida por otra mano, cuando el gesto excede la firmeza de un apretón de manos. Tal vez es necesario sacudir algo más que una mano. Si un manifiesto aguafiestas es algo de dónde agarrarse, se escapa de nuestras manos. Un manifiesto, entonces, repite algo que ya ha sucedido; como sabemos, la aguafiestas perdió los estribos, salió volando. Quizás un manifiesto aguafiestas sea incómodo o inasible; una fuga feminista.

Cuando nos rehusamos a ser las herramientas del amo, exponemos la violencia de los palos, ${ }^{13}$ las violencias que construyen la casa del amo, ladrillo a ladrillo. Cuando ponemos de manifiesto la violencia, una violencia que se reproduce al no ser puesta de manifiesto, seremos designadas como aguafiestas. Antes que nada, una aguafiestas se convierte en aguafiestas por lo que revela. Un manifiesto está, en cierto sentido, detrás de ella. Esto no quiere decir que escribir un manifiesto aguafiestas no sea también un compromiso; que no sea también una idea acerca de cómo seguir adelante. Una aguafiestas tiene sus principios. Un manifiesto aguafiestas muestra cómo creamos principios a partir de la experiencia de enfrentarse con algo, a partir de cómo vivimos una vida feminista. Cuando digo principios aquí, no me refiero a reglas de conducta que debemos aceptar para poder avanzar en una dirección común. Diría

13 N. de la T.: La palabra inglesa rods se traduce aquí como "palos", pero conviene aclarar que en inglés vulgar la palabra significa también "pistola" y "pene". 
que una vida feminista tiene principios, pero el feminismo a menudo se convierte en una declaración en el momento mismo en que rechaza regirse por ciertos principios. Cuando pienso en principios feministas, pienso en los principios en su sentido original: principio como primer paso, como inicio, como el comienzo de algo.

Un principio puede ser lo que es elemental para una habilidad. Las feministas aguafiestas y otrxs sujetxs obstinadxs son habilidosxs; nos estamos volviendo habilidosxs. Hay principios en lo que hacemos. El modo en que comenzamos no determina a dónde terminaremos, pero los principios dan forma o dirección. Los principios feministas se articulan en mundos no feministas. Vivir una vida con principios feministas es, por lo tanto, no vivir sin problemas; nos chocamos con el mundo que no vive de acuerdo con los principios con los que tratamos de vivir.

Por alguna razón, los principios que articulo aquí terminaron siendo expresados como declaraciones de voluntad: qué está dispuesta (a hacer o ser) o no está dispuesta (a hacer o ser) una aguafiestas. Pienso que podemos comprender algo de esta lógica. Un manifiesto aguafiestas es un sujeto aguafiestas; su voluntad es equívoca por lo que desea o no desea hacer. Sin dudas que un sujeto obstinado tiene principios; ella puede ser una persona de principios. Ella puede compartirlos, si vos podés aguantarlos.

\section{PRINCIPIO 1. No estoy dispuesta a hacer de la felicidad mi causa}

A menudo se hace un requerimiento específico: te piden que hagas algo para hacer felices a otras personas. Es más probable que te pidan que hagas algo para hacer felices a otras personas cuando saben que no te hace feliz lo que están haciendo. Quizás, quienes saben que estás en contra de la institución del matrimonio, te pidan que participes de un casamiento, de una ceremonia que celebra esa institución. Apelan a vos apelando a su propia felicidad. Si rechazás esa apelación, te consideran egoísta, como si antepusieras tu propia felicidad a la felicidad ajena.

Mala: ¿cómo pudiste?

Un manifiesto aguafiestas: hacer sentido siendo mala.

Si estás dispuesta a rechazar estos llamamientos, entonces la felicidad no es el principio que defendés. No te parece que ese llamamiento sea llamativo. Y no defendés este principio en general porque te has enfrentado con este principio antes: te han pedido que no digas ciertas cosas, que hagas cosas, porque harías infelices a otras personas. No se desprende de esto que a una aguafiestas no le importe la felicidad de las otras personas, o que ella no pueda en algunos momentos decidir hacer algo porque contribuye a la felicidad ajena. Simplemente, ella no está dispuesta a que causar felicidad sea su causa política.

A partir de esta situación cotidiana de vivir con las consecuencias de no hacer de la felicidad tu causa, aprendés acerca de la infelicidad que puede causar la felicidad. Este primer principio ha sido la base para una gran parte del conocimiento y el activismo feminista: identificar cómo las instituciones están construidas como promesas de felicidad; promesas que a menudo ocultan la violencia de esas instituciones. Estamos dispuestas a exponer esta violencia: la violencia del encumbramiento de la familia, del formato de la pareja, de la reproducción como la base de la buena vida; la violencia reproducida por las organizaciones que consideran desleal hablar de la violencia. Vamos a exponer los mitos de la felicidad del neoliberalismo y del capitalismo global: 
la fantasía que el sistema creó para unxs pocxs privilegiadxs es, en verdad, algo que afecta la felicidad de muchxs o de la mayoría.

Exponer los mitos de la felicidad es estar dispuesta a que te designen como aguafiestas.

\section{PRINCIPIO 2. Estoy dispuesta a causar infelicidad}

No hacer de la felicidad tu causa puede causar infelicidad. Una aguafiestas está dispuesta a causar infelicidad.

Una aguafiestas comprometida tiene una vida entera de experiencia en ser la causa de la infelicidad. Y ella sabe esto también: cuando causás infelicidad, por causa de tus deseos o de los mundos que no querés adoptar como propios, se asume que la infelicidad es tu causa. No lo es. Que estés dispuesta a causar infelicidad no significa que la infelicidad sea tu causa, aunque vivimos con la presuposición de que la infelicidad es nuestra causa. Cuando nuestros deseos causan infelicidad, a menudo se presume que deseamos causar infelicidad. Puede ser que te juzguen como si quisieras la infelicidad que causás, y esta es otra manera en que te convertís en la causa de la infelicidad.

Una aguafiestas está dispuesta a vivir con las consecuencias de eso a lo que está dispuesta. Ella está dispuesta, entonces, a ser la causa de la infelicidad de alguien más. No significa que ella no se pondrá triste porque otra gente está triste por su vida (porque piensan que su vida es triste); no significa, incluso, que ella no vaya a sentir compasión hacia quienes se volvieron infelices a causa de su vida. Ella no va a permitir que esa infelicidad la redirija. Ella está dispuesta a ser desviada.

¿A quienes estamos dispuestas a causarles infelicidad? A nadie: esa es la única respuesta a esta pregunta. Pero hay una afirmación condicional aquí. Estamos dispuestas a causar infelicidad institucional si la institución muestra descontento porque hablamos sobre el acoso sexual. Estamos dispuestas a causar infelicidad entre las feministas si muestran descontento porque hablamos sobre racismo. Esto significa: nos provoca descontento esta afirmación condicional. Esto significa: nos provoca descontento lo que causa infelicidad. Revelar las causas de la infelicidad puede causar infelicidad.

Estamos dispuestas a causar infelicidad debido a lo que aprendimos de la infelicidad a partir de lo que se supone que causamos. Un "yo" surge aquí; ella sabe lo que está pasando a partir de lo que surge. Cuando hablé públicamente sobre acoso sexual en mi facultad, fui identificada por algunas personas como una aguafiestas sin ningún sentido de la ironía (puede ser que haya habido algún sentido de la ironía, dado que ya había afirmado que era una aguafiestas). Lo que es importante notar es que había algunas feministas entre estas personas. Una colega feminista dijo que al hablar públicamente estaba poniendo en peligro el "feliz y estimulante" ambiente que las "feministas históricas" habían creado con su trabajo. Asumí que yo no era una de las feministas históricas por la posición que tomé. Sí, incluso hablar de acoso sexual puede causar infelicidad feminista. Si es así, entonces: no estoy dispuesta a hacer de la felicidad feminista mi causa.

Aprendimos a escuchar lo que está en juego en estas acusaciones. El feminismo es, implícitamente, una burbuja dentro de la institución. Pero una burbuja feminista puede también operar como una forma de identificación. Para proteger la burbuja feminista quizás quieras protegerla de la exposición a la violencia de la institución, una violencia que está ocurriendo en otra parte (otro centro, otro departamento). Proteger la burbuja feminista termina siendo un medio para proteger la institución. 
No querés que la violencia institucional quede expuesta. Preferirías resolver la violencia "en casa", incluso cuando este "en casa" fracasó en desmantelar la casa del amo. ¿Es por eso que hay tanto secretismo y silencio sobre la violencia institucional, incluso entre feministas?

\section{Si el feminismo es una burbuja, necesitamos que esa burbuja reviente.}

Cuando dejamos de lado lo que pone en riesgo nuestra felicidad, estamos quitando nuestros esfuerzos a un trabajo que necesita ser realizado para permitir un mundo más justo y equitativo. Pero este principio de estar dispuesta a causar infelicidad no puede ser sostenido asumiendo que se refiere solo a la infelicidad ajena. Es posible que no registremos algunas situaciones porque registrarlas nos haría infelices. Quizás es por eso que aparecen las aguafiestas: porque nos desesperamos por no registrar lo que ella percibe. Quizás esta es la razón por la cual la aguafiestas se aparece a quienes manifiestan ser aguafiestas: nuestra felicidad también puede depender de lo que no percibimos. Debemos rechazar este olvido. Si algo pudiera hacernos infelices al reconocerlo, debemos reconocerlo. Estamos dispuestas a causar nuestra propia infelicidad, pero eso no hace de la infelicidad nuestra causa.

\section{PRINCIPIO 3. Estoy dispuesta a apoyar a quienes están dispuestxs a causar infelicidad}

Una aguafiestas podría reconocerse primero en este sentimiento de soledad: de ser dejada de lado por otras personas, apartada de cómo se reúnen en torno a la felicidad. Ella lo sabe, porque ya estuvo ahí: no sentarse en las mesas de la felicidad puede significar encontrarte a vos misma en un lugar lúgubre, encontrarte sola, sin ayuda. Puede ser que muchas personas pasen por la figura de la aguafiestas y rápidamente la abandonen porque descubren que es un lugar difícil para estar; no rodearte de la calidez de otras personas, ni de los murmullos tranquilos que acompañan un acuerdo. Los costos de aguar fiestas son altos; esta figura en sí misma es costosa (no acordar con alguien equivaldría a aguar la fiesta de algo).

¿Cómo persistís? Como sugerí en mi kit de supervivencia, a menudo persistimos al encontrar la compañía de otrxs aguafiestas; podemos tomar este nombre cuando reconocemos las dinámicas que nombra; y podemos reconocer esa dinámica cuando otras personas articulan esa dinámica para nosotras. Reconocemos a otras personas porque reconocen esa dinámica.

Esos momentos de reconocimiento son preciosos; y son precarios. Con un momento viene un recuerdo: a menudo persistimos porque recibimos apoyo de otras personas. Es posible, también, que experimentemos la crisis de no tener apoyo; el apoyo importa mucho más cuanto menos apoyo sentimos. Hacer un manifiesto a partir de la aguafiestas significa estar dispuesta a dar a otras personas el apoyo que recibiste o deseaste recibir. Quizás estás en una conversación, en tu casa o en el trabajo, y una persona, una persona entre muchas, alza la voz, protesta. No la dejes hablando sola. Secundala; hablá junto con ella. Apoyala; quedate con ella. A partir de estos momentos públicos de solidaridad se crean muchas cosas. Estamos creando un sistema de apoyo en torno a la aguafiestas; estamos encontrando maneras de permitir que ella haga lo que hace, que sea lo que es. No tenemos que asumir su permanencia, ni convertir su figura en una identidad, para saber que cuando ella surge puede necesitar de otras personas que la apoyen. 
Audre Lorde una vez escribió, "Tu silencio no te protegerá" (1984: 41). Pero tu silencio puede proteger a ciertas personas. Y por ciertas personas quiero decir: quienes son violentos o quienes se benefician de alguna manera del silencio acerca de la violencia. La aguafiestas es testimonio. Ella surge como una figura, una manera de contener el daño, porque ella habla acerca del daño. Con el tiempo, el tiempo de ser feminista - podemos llamarlo el tiempo feminista - he llegado a entender, a saber y a sentir, los costos de alzar la voz. He llegado, así, a comprender, a saber y a sentir, por qué muchas personas no alzan su voz. Hay mucho que perder, mucho, incluso la vida. Tanta injusticia se reproduce a través del silencio, no porque las personas no reconozcan la injusticia, sino porque la reconocen. También reconocen las consecuencias de identificar la injusticia, y puede que no sean consecuencias con las que puedan vivir. Puede ser miedo a perder tu trabajo y saber que necesitás ese trabajo para sostener a quienes querés; puede ser la preocupación de perder conexiones que te importan; preocupación porque lo que digas será entendido erróneamente; preocupación de que, si decís algo, podés hacer que las cosas estén peor. Sugerir que la feminista aguafiestas es un manifiesto, no es decir que tenemos la obligación de alzar la voz. No todas estamos en la misma posición; no todas podemos permitirnos alzar la voz. Aguar la fiesta requiere, entonces, un sistema de comunicación: tenemos que encontrar otras maneras de hacer que la violencia se ponga de manifiesto. Puede ser que necesitemos usar tácticas de guerrilla, y tenemos una historia feminista a la cual recurrir aquí; podés escribir los nombres de los acosadores en los libros; hacer grafitis en las paredes; poner tinta roja en el agua. Hay tantas maneras de causar una perturbación feminista.

Incluso si levantar la voz no es posible, es necesario. El silencio en torno a la violencia es violencia. Pero el discurso feminista puede tomar muchas formas. Nos hacemos más creativas con las formas cuanto más difícil es salir adelante. Alzar la voz y hablar con otras personas, proteger a quienes hablan; estos actos que hacen correr la voz construyen mundos. Aguar fiestas es un proyecto que construye un mundo. Hacemos un mundo a partir de las piezas rotas, incluso cuando nosotras mismas rompemos las piezas o incluso cuando las piezas rotas somos nosotras.

\section{PRINCIPIO 4. No estoy dispuesta a reírme de chistes destinados a ofender}

Este principio puede parecer muy específico: puede parecer que se deriva de mis tres principios iniciales y que no merece ser un principio en sí mismo. Pero pienso que el humor es una técnica muy crucial para reproducir la desigualdad y la injusticia. Pienso que la fantasía de la feminista sin humor - como parte de una fantasía más generalizada acerca de la falta de humor de quienes cuestionan los órdenes tanto sociales como políticos- hace un trabajo sumamente importante. La fantasía es lo que hace que la figura de la aguafiestas haga su trabajo. Se presume que ella dice lo que hace (señalar el sexismo, señalar el racismo) porque carece de alegría, porque no puede soportar la alegría de las otras personas. A menudo, una vez que se designa a alguien como feminista aguafiestas, entonces se harán ciertos chistes, para que se ofenda, para ser testigos de su mal humor. No caigas en la tentación de reír. Si la situación no tiene gracia, no necesitamos agregarle humor. Si la situación no es graciosa, no necesitamos alivianarla; no necesitamos hacerla divertida.

Es a menudo a través del humor (digamos, a través de la ironía y de la sátira) que las personas pueden continuar haciendo declaraciones sexistas y racistas. El humor crea la apariencia de una distancia; al reírse de lo que repiten, repiten aquello de lo que se 
están riendo. La broma se hace a costa de eso. No es una cuestión risueña. Cuando no es una cuestión risueña, las risas importan.

Pero, por supuesto, el humor puede cuestionar cosas al traerlas a la superficie; señalé esto en mi kit de supervivencia. Pero hay diferencias que importan en lo que hace a la risa. El humor feminista puede involucrar el alivio de poder reírse cuando se revelan patrones familiares que a menudo están ocultos. Podemos reírnos de cómo los hombres blancos se unen al reducir cualquier cosa que hacemos como "no hombres blancos" a políticas de la identidad. Podemos reírnos, incluso, cuando nos reducen a ser un póster de la diversidad; y reírse no significa que no experimentemos dolor y frustración cuando las instituciones nos llaman para proveerlas de rostros coloridos y sonrientes; para hacer suyos nuestros rostros. Pero esta no es la clase de risa que nos hace repetir lo que causa la ofensa; es una reorientación hacia esta causa. No la repetimos; nos retiramos.

La aguafiestas existe en cercana proximidad a la figura de la persona demasiado sensible, quien se ofende con demasiada facilidad. Esta figura es evocada siempre que la crítica social es exitosa: que algo se ha cerrado, eliminado o perdido (una pérdida que es lamentada) porque otras personas se sintieron ofendidas, donde sentirse ofendidx es sentirse ofendidx con demasiada facilidad, ser débil, ser blandengue, ser impresionable. "Endurecete" se ha convertido en un imperativo moral, uno que es (como la mayoría de los imperativos morales) articulado por quienes creen que tienen lo que, a su juicio, las otras personas necesitan. De hecho, esta figura de la persona demasiado sensible puede surgir antes de la pérdida, o para evitar la pérdida. El pánico moral sobre las "advertencias de detonantes" (trigger warnings) a menudo evoca esa figura, específicamente la del estudiantado demasiado sensible que no está en sintonía con las dificultades y la incomodidad de aprender, como si se dijera: si dejamos que tu sensibilidad se convierta en ley, perdemos nuestra libertad. Argumentaría que la libertad se ha reducido a la libertad de ofender, algo que se trata también de cómo quienes tienen poder protegen su derecho a articular sus propios puntos de vista, sin importar nada, ni nadie.

Si por no querer que las historias que son violentas se repitan con violenta insistencia, o simplemente por hacer preguntas sobre las condiciones que permiten la repetición, vamos a creer que somos demasiado sensibles, necesitamos ser demasiado sensibles. Cuando sos sensible a lo que no ha dejado de repetirse, te consideran demasiado sensible. Somos sensibles a aquello que no ha terminado. Somos sensibles porque no se terminó.

\section{PRINCIPIO 5. No estoy dispuesta a superar historias que no están superadas}

Aún no se terminó. Decimos eso, con insistencia, mientras vemos que otras personas declaran que las cosas han terminado. Tantas declaraciones, y forman parte de la misma cosa. El actual primer ministro inglés, David Cameron, dice que una de las cosas que hizo grande a Gran Bretaña fue que "sacamos la esclavitud de alta mar". Gran Bretaña es recordada como liberadora de lxs esclavxs, y no como perpetradora de la esclavitud; ni como un país que se benefició de la esclavización masiva de otras personas, de la colonización de otras personas. En el libro sobre el cual se basan las pruebas de ciudadanía en el Reino Unido, el colonialismo se describe como el sistema que introdujo la democracia, y el derecho, aportando beneficios para otras personas. Una historia violenta de conquista y robo es imaginada como el regalo de 
la modernidad. Y, el día de hoy, las guerras son aún justificadas como regalos, como formas de dar libertad, democracia e igualdad.

\section{Cuando no se ha superado, no es momento para superarlo.}

Una aguafiestas está dispuesta a poner esta historia sobre la mesa. Un recuerdo puede ser obstinado. Y, entonces, sabemos lo que pasa cuando hacemos esto. Te acusan como si fueras quien entorpece la reconciliación. Te juzgan como la persona que todavía tiene que hacer lo que otras personas ya hicieron: superalo; superate; olvidate. Te convertís en la herida abierta porque no dejás que las cosas se sanen.

Estamos dispuestas a ser quienes hacen fracasar el proyecto de reconciliación. Sabemos que el éxito de ese proyecto es el fracaso de afrontar estas historias de injusticia que se manifiestan no solo en el trauma irresuelto de quienes reciben esta historia como una herencia corporal y como un tormento intergeneracional, sino también como una distribución groseramente desigual de la riqueza y los recursos.

\section{Cómo se conforma un mundo es memoria.}

Y dicen: pero mirá lo que te han dado. Igualdad, diversidad: todo se convierte en regalos por los cuales se supone que deberíamos sentir agradecimiento; se transforman en una compensación. No sentimos agradecimiento cuando un sistema se expande para incluirnos, cuando ese sistema está basado en la desigualdad y la violencia.

\section{PRINCIPIO 6. No estoy dispuesta a ser incluida si la inclusión signi- fica que te incluyan en un sistema que es injusto, violento y desigual}

Es a menudo una invitación: vení, formá parte, sé agradecida. A veces, tenemos pocas opciones: somos trabajadoras; trabajamos; nos las arreglamos con lo que hay. Tenemos que sobrevivir o, aun, progresar en una institución. Pero incluso quienes estamos incluidas, incluso si recibimos beneficios (puede ser que tengamos un salario; puede ser que tengamos una pensión), no deseamos esa inclusión: estamos aceptando que la inclusión requiere respaldar a la institución, identificarse con ella. Deseamos levantar la voz sobre la violencia del sistema, hacer huelga, protestar. Deseamos hablar sobre los palos, arriesgarnos a ser identificadas como un brazo rebelde.

Pero hay una dificultad aquí. Porque seguramente si te emplea una organización, si recibís los beneficios del empleo, puede decirse que mantener una postura aguafiestas es una forma de deshonestidad política: obtenés beneficios de las instituciones que criticás. Necesitamos comenzar por nuestra propia complicidad: esta es la razón por la cual la parte II comenzó por la naturaleza comprometida del trabajo en el ámbito de la diversidad. Ser cómplice no debería convertirse en su propia lógica reproductiva: que todo lo que podamos hacer sea reproducir la lógica de las instituciones que nos emplean. En verdad, quienes se benefician de un sistema injusto necesitan trabajar más fuerte para exponer esa injusticia. Para las aguafiestas que tienen un empleo regular-llamémonos aguafiestas profesionales; puede ser que seamos, incluso, profesoras aguafiestas - cuando afirmamos que somos aguafiestas no hay otra manera de superar esta dificultad si no es empezando por ella. Necesitamos usar los beneficios que recibimos para apoyar a quienes no reciben esos beneficios, incluyendo a quienes dentro de nuestras propias instituciones no tienen las seguridades que nos dan la oportunidad de exponer esas inseguridades. En la educación superior, esto significa que tenemos que poner en acto nuestra solidaridad con el estudiantado que está luchando por la educación como un derecho, con lxs profesorxs temporarixs que no 
tienen estabilidad en el cargo o que tienen contratos de corto plazo, con el personal profesional que hace el trabajo de mantener los edificios e instalaciones en los que hacemos nuestro trabajo: personal de limpieza, de seguridad, conserjes. He tratado de mostrar cómo el aguar la fiesta y la obstinación también se conectan con las políticas del trabajo: los brazos importan, lo que es decir que ciertas personas terminan haciendo el trabajo de reproducir las condiciones que permiten la existencia de otras personas. Cuando nuestra existencia profesional es posible por el trabajo de otras personas, necesitamos usar nuestra existencia para reconocer ese trabajo. Necesitamos exponer la injusticia de las instituciones que dan apoyo a algunas personas quitándole el apoyo a otras. Y necesitamos dar apoyo a quienes desafían las condiciones bajo las cuales trabajan sin apoyo. La obstinación es asombrosa.

Y debemos continuar exponiendo la violencia en las instituciones que nos han incluido, especialmente cuando nuestra propia inclusión ocurre bajo el signo de la diversidad y de la igualdad, especialmente cuando nuestros cuerpos y los productos de nuestro trabajo son usados por las instituciones como evidencia de la inclusión. Nos convertimos en rompemuros. Entonces, tenemos que hablar acerca de los muros; tenemos que mostrar cómo la historia se hace concreta. No vamos a permitir que nuestra inclusión respalde una fantasía de felicidad. Puede que necesitemos irnos, en cierto punto, si nuestra inclusión significa renunciar demasiado, aunque no todas estamos en una posición que nos permita irnos.

Un manifiesto aguafiestas: requiere un rechazo continuo y obstinado a identificar nuestras esperanzas con la inclusión en organizaciones basadas en la violencia. No estoy agradecida por ser incluida en una institución en la que hablar sobre sexismo y racismo es escuchado como una actitud desagradecida. Tenemos una historia de feministas desagradecidas para inspirarnos. Feministas desagradecidas; gruñonas; enojonas.

Todo junto: las gruñonas son el lumpen feminista. Un lumpenproletariado: con forma de feminista y con una conciencia feminista.

\section{PRINCIPIO 7. Estoy dispuesta a vivir una vida que otra gente considera infeliz y estoy dispuesta a rechazar o ampliar los guiones disponibles acerca de lo que cuenta como una buena vida}

Ya he señalado que la felicidad involucra el estrechamiento de las formas de vivir una vida. Podemos ser desleales si rechazamos que nos estrechen. Vivimos vidas que para otras personas no son felices, que no alcanzan los puntos convencionales de ceremonia. Dos mujeres que viven juntas, que rechazan tener una unión civil, que se rehúsan a casarse; estamos poniendo en práctica nuestro rechazo al heteropatriarcado. Poner en práctica un rechazo es una acción que se realiza con otras personas.

Podemos llegar a encarnar un linaje familiar alternativo, como sugerí en el capítulo 8 , o una alternativa al linaje familiar. Me gusta mucho ser una tía feminista lesbiana. Sé que siendo una mujer joven me hubiera gustado tener unas tías feministas lesbianas, aunque ciertamente tuve tías feministas a quienes les debo mucho. Necesitamos contar nuestras historias a la infancia, a quienes están por venir; las generaciones necesitan contarse mutuamente historias, reunidas en torno a otras vidas, aquellas que se desvanecen por la falta de palabras. Necesitamos contarnos mutuamente historias acerca de las diferentes formas en que podés vivir, diferentes maneras de ser; que no estén basadas en cuánto te acerques a la vida que se asume o se espera que tengas, sino en los vagabundeos queer de la vida que vivís. 
Me hubiera gustado saber que había otras formas de vivir, de ser. Me hubiera gustado saber que las mujeres no tenían que estar en relación con los hombres. Por supuesto, luché para llegar a comprender: me hice feminista; encontré los Estudios de las Mujeres; conocí a mujeres que me enseñaron lo que no tenía que hacer; encontré mujeres que me ayudaron a desviarme de una expectativa.

Queer: el momento en que comprendés lo que no tenías que ser.

Podemos ser parte de una ampliación cuando rechazamos que nos estrechen. Y cada vez que rechazamos o ampliamos el guion de la felicidad, nos convertimos en parte de una apertura. Tenemos que crear espacio si vamos a vivir una vida feminista. Cuando creamos espacio, creamos espacio para otras personas.

\section{PRINCIPIO 8. Estoy dispuesta a devolverle el azar a la felicidad}

Señalé cómo la palabra happiness ("felicidad") se deriva de la palabra del inglés medio hap, que significa azar o suerte. Una historia de la felicidad es la historia de la eliminación de este azar, tal que esa felicidad no es definida en términos de lo que te pasa sino en función de lo que te esforzás para que pase. En mi libro The Promise of Happiness examiné cómo la felicidad termina siendo redefinida contra el azar, especialmente en la psicología de los flujos y la psicología positiva: no como algo que sucede (o simplemente sucede). Los estrechos guiones de la felicidad se tratan, precisamente, de la violencia de la eliminación del azar. Necesitamos reconocer la eliminación del azar antes de poder restaurar el azar. No podemos simplemente usar la palabra a la ligera como si pudiera sacarnos de aquí. Tenemos que reconocer el peso del mundo, el peso de la felicidad, y cómo somos abatidas por las expectativas de que somos un bajón. Nos tropezamos. Cuando nos tropezamos, cuando nos alineamos, podemos sentir que somos un obstáculo para nuestra propia felicidad; podemos sentir que somos quienes nos entorpecemos el paso. ¿Podemos permitirnos obstaculizar el paso? ¿Puede ser que deseemos lo que parece que estamos deshaciendo? Me tropiezo; tal vez al tropezarme te encuentre, tal vez al tropezarme me tropiece con la felicidad, una felicidad llena de azar; una felicidad que es tan frágil como los cuerpos que amamos y cuidamos. Valoramos esa felicidad porque es frágil: viene y se va, como lo hacemos nosotrxs. Estoy dispuesta a dejar que la felicidad se vaya; a permitir que el enojo, la ira, o la decepción sean el modo en que soy afectada por un mundo. Pero cuando la felicidad sucede, soy feliz.

Una felicidad frágil puede estar en sintonía con la fragilidad de las cosas. Podemos preocuparnos por las cosas que se rompen, por las cosas rotas. Cuidar de tales cosas no es preocuparse por la felicidad. Preocuparnos por la felicidad puede, muy a menudo, traducirse en cuidar de otras personas bajo la condición de que reflejen tu idea acerca de cómo la vida debe ser vivida. Quizás podamos pensar el cuidado en relación con el azar. A menudo se da por sentado que somos negligentes cuando rompemos algo, como señalé en el capítulo 7. ¿Qué puede significar cuidar de algo, se rompa o no? Quizás podemos reorientar el cuidado, en vez de cuidar la felicidad de alguien puede ser cuidar de lo que le pase a algo o a alguien. Podríamos llamarlo "cuidado del azar" en lugar de "cuidado de la felicidad". Un cuidado del azar no sería dejar ir un objeto, sino aferrarse a un objeto dejándose ir a una misma, entregarte a algo que no es tuyo. Un cuidado del azar no trataría de eliminar la ansiedad del cuidado; podría incluso ser descripto como un cuidado para el azar. El cuidado es ansioso - estar llena de cuidados, ser cuidadosa, es cuidar de las cosas teniendo ansiedad sobre su futuro; futuro que encarna en la fragilidad de un objeto cuya persistencia importa-. Nuestro cuidado puede recoger las piezas de un recipiente destrozado. 
Nuestro cuidado no puede convertir el objeto en un monumento, sino que valorará cada pieza; el destrozo como el comienzo de otra historia.

Pero no vamos a terminar con una noción liberal: todo es igualmente frágil; debemos cuidar de todo por igual. No es así; no lo haré. Algunas cosas se hacen más frágiles que otras con el tiempo. Con tiempo, nos ocupamos. Ocuparse de algo que se ha hecho frágil es ocuparse de su historia, con amor, con cuidado.

\section{PRINCIPIO 9. Estoy dispuesta a romper cualquier vínculo, por preciado que sea, cuando esos vínculos me dañan o dañan a otras personas}

Tantas veces me han dicho que es triste cuando un vínculo se ha roto, como mencioné en el capítulo 8. Pero los vínculos pueden ser violentos. Un vínculo puede disminuirte. A veces no estamos preparadas para reconocer que hemos sido disminuidas. No estamos listas. Llegar a estar lista para romper ese vínculo puede tomar tanto trabajo psíquico como político. Cuando lo hacés, cuando lo rompés, puede sentirse como un momento inesperado que rompe una línea que se ha estado desarrollando en el tiempo, una desviación, una partida. Pero un momento puede ser un logro; puede ser eso por lo que estuviste trabajando.

Puede ser que estés dispuesta a romper el vínculo. Puede ser que necesites ser obstinada para desearlo. Y puede ser que necesites reconocer que otras personas también necesitan trabajar para llegar al punto en que pueden abandonarlo. Compartí ese trabajo. Tenemos que compartir los costos de nuestra renuncia. Pero cuando renunciamos, no solo perdemos algo, incluso si perdemos algo. Encontramos cosas. Descubrimos cosas que antes no conocíamos sobre nosotras, sobre los mundos. Una vida feminista es un viaje, es alcanzar algo que puede que no hubiera sido posible alcanzar sin una ruptura, sin el enérgico apoyo de otras personas. Pero una vida feminista es también ir para atrás, recuperar partes de nosotras mismas que no sabíamos que teníamos, que no nos dimos cuenta que habíamos dejado en suspenso.

Podemos sostenernos mutuamente si no nos dejamos en suspenso.

\section{PRINCIPIO 10. Estoy dispuesta a participar en un movimiento aguafiestas}

Seas o no seas una persona difícil, se te percibe como si hicieras las cosas difíciles para vos y para las demás personas. Con tantas dificultades, podrías pensar que las feministas aguafiestas se van a dar por vencidas. Sin embargo, cuando empecé a presentar y a hablar sobre la feminista aguafiestas, cuando empecé a trabajar con ella y sobre ella, a recogerla, me di cuenta de que los lugares se llenaban de energía. A veces hablar de ella, dejarla entrar a la habitación para que haga lo suyo, se sentía como un shock eléctrico. Y ella se encuentra rápidamente en compañía de otras aguafiestas: aguafiestas transfeministas (Cowan, 2014), aguafiestas étnicas (Khorana, 2013), aguafiestas tullidas (Mullow, 2013), aguafiestas feministas indígenas (Barker, 2015). Va a haber más, estoy segura.

¿Por qué? Porque la figura de la aguafiestas surge siempre que hay historias difíciles de poner sobre la mesa. La aguafiestas es atractiva no a pesar de lo que saca a relucir sino, justamente, por lo que saca a relucir. Ella adquiere vitalidad o energía de una 
escena de dificultad. Estar dispuesta a ser una aguafiestas, estar dispuesta a ponerse en el camino de la felicidad, se agarra a un criterio y lo lleva a cabo.

Incluso transformamos el criterio en una orden rebelde.

¿Aguafiestas?

Solo mirame.

¡Vamos!

Puede ser un gran aprendizaje cuando la recogemos. Puede haber alegría en encontrar aguafiestas; puede haber alegría en aguar fiestas. Nuestros ojos se encuentran cuando nos contamos acerca de los ojos que se ponen en blanco.

Vos también; vos también.

Un movimiento frágil.

Enérgico y rápido como un chasquido.

Tantos momentos son abreviados en nuestra ecuación "ojos en blanco = pedagogía feminista". Estamos deseando esos momentos. Los momentos se pueden convertir en movimiento. Los momentos pueden construir un movimiento, un movimiento hecho de materiales livianos. Esta no es una morada segura. Estamos destrozadas, muy a menudo; pero mirá como se mueven los muros.

Estamos deseosas de participar en el movimiento aguafiestas.

Somos ese movimiento.

Mirá cómo nos movemos. 


\section{Dibliografía}

"Ahmed, S. (2010). The Promise of Happiness. Durham, Duke University Press. [ La promesa de la felicidad. Una crítica cultural al imperativo de la alegría. Salas, H. (trad.). Buenos Aires, Caja Negra, 2019].

"Barker, J. (2015). The Indigenous Feminist Killjoy. Tequila Sovereign, 24 de julio. En línea en: https://tequilasovereign.com/2015/07/24/the-indigenous-feministkilljoy/

»Butler, J. (1990). Gender Trouble: Feminism and the Subversion of Identity. Nueva York, Routledge. [El género en disputa. El feminismo y la subversión de la identidad. Muñoz, M.A. (trad.). Barcelona, Paidós, 2007].

" ------ (1993). Bodies That Matter: On the Discursive Limits of "Sex". Londres, Routledge. [Cuerpos que importan. Sobre los límites materiales y discursivos del \sexo囚. Bixio, A. (trad.). Buenos Aires, Paidós, 2002].

"------ (2015). Notes Towards a Performative Theory of Assembly. Cambridge, Harvard University Press. [Cuerpos aliados y lucha política. Hacia una teoría performativa de la asamblea. Viejo Pérez, M. (trad.). Buenos Aires, Paidós, 2017].

"Cowan, T. L. (2014). Trans/Feminist Killjoys: Rage, Love and Reparative Performance. Transgender Studies Quarterly, vol. 1, núm. 4, pp. 501-516, noviembre.

» Davis, A. (1998 [1989]). Blues Legacies and Black Feminism: Gertrude "Ma" Rainey, Bessie Smith and Billie Holiday. Nueva York, Vintage.

"De Beauvoir, S. (1997 [1949]). The Second Sex. Parshley, H. M. (trad.). Londres, Vintage. [El segundo sexo. García Puente, J. (trad.). Buenos Aires, De Bolsillo, 2011].

"Firestone, S. (1970). The Dialectic of Sex: The Case for Feminist Revolution. Nueva York, Bantam. [La dialéctica del sexo. Ribé Queralt, R. (trad.). Barcelona, Kairós, 1976].

"Franklin, S. (2010). Revisiting Reprotech: Firestone and the Question of Technology. En Merck, M. y Stanford, S. (eds.). Further Adventures on the Dialectic of Sex: Critical Essays on Shulamith Firestone, pp. 39-59. Londres, Palgrave Macmillan.

》 Gilmore, R. W. (2007). Golden Gulag: Prisons, Surplus, Crisis, and Opposition in Globalizing California. Berkeley, University of California Press.

" Goldman, E. (2008 [1931]). Living My Life, vol. 1. Nueva York, Cosimo. [Viviendo mi vida, vol. 1. Useros, A. (trad.). Madrid, Capitán Swing y Fundación Anselmo Lorenzo, 2014].

»Gumbs, A. P. (2010). We Can Learn to Mother Ourselves: The Queer Survival of Black Feminism, 1968-1996. Tesis de Doctorado. Duke University.

" Haraway, D. (2003). A Companion Species Manifesto: Dogs, People and Significant Otherness. Chicago, Prickly Pradigm. [Manifiesto de las especies de compañía. Perros, personas y la alteridad significativa. Mellén, I. (trad.). Bilbao, Sans Soleil, 2016].

"Khorana, S. (2013). On Being and Ethnic Killjoy in the Asian Century. The Conversation, 19 de noviembre. En línea en: http://theconversation.com/on- 
being-an-ethnic-killjoy-in-the-asian-century-19833

» King, M. (2013). Revenge as a Radical Feminist Tactic in the SCUM Manifesto. No More Potlucks, julio/agosto. En línea en: http://nomorepotlucks.org/site/ revenge-as-radical-feminist-tactic-in-the-scum-manifesto-moynan-king/

"Lorde, A. (1978). Black Unicorn. Nueva York, Norton.

"-------- (1984). Sister Outsider: Essays and Speeches. Trumansburg, Crossing Press. [La hermana, la extranjera. Artículos y conferencias. Corniero, M. (trad.). Madrid, Horas y Horas, 2003].

»-------- (1988). A Burst of Light: Essays. Ithaca, Firebrand.

"-------- (1997). The Cancer Journals. San Francisco, Aunt Lute. [Los diarios del cáncer. Adelstein, G. (trad.). Rosario, Hipólita Ediciones, 2008].

»Millbank, L. (2013). The Scope of Action, Smiling, Smile 'Strikes' and Individual Action. Radtransfem, enero. En línea en: https://radtransfem.tumblr.com/ post/40249024485/the-scope-of-action-smiling-smile-strikes-and

" Mullow, A. (2013). Bellyaching. Social Text, 24 de octubre. Disponible en: https:// socialtextjournal.org/periscope_article/bellyaching/

»Puar, J. (2009). Prognosis Time: Towards a Geo-politic of Affect, Debility and Capacity. Women and Performance: A Journal of Feminist Theory, vol. 19, núm. 2, pp. 161-172, julio.

» Rich, A. (1979). Disloyal to Civilization. En On Lies, Secrets and Silence: Selected Prose, 1966-1978. Nueva York, Norton.[Sobre mentiras, secretos y silencios. Dalton, M. (trad.). Madrid, Horas y Horas, 2011].

"Solanas, V. (2013 [1967]). SCUM Manifesto. Chico, AK Press. [Scum. Manifiesto de la Organización para el Exterminio del Hombre. Becciú, A. (trad.). Madrid, Kira, 2002]. 